UNIVERSIDADE DE BRASÍLIA

FACULDADE DE TECNOLOGIA DEPARTAMENTO DE ENGENHARIA ELÉTRICA

CONVERGÊNCIA E INTEROPERABILIDADE ENTRE A REDE DE TELEFONIA FIXA COMUTADA E A REDE IP

\author{
FELIPE PÓVOA ARAÚJO \\ MARIA CECÍLIA DA COSTA BRAGA
}

ORIENTADOR: FLÁVIO ELIAS GOMES DE DEUS

MONOGRAFIA APRESENTADA COMO REQUISITO PARCIAL PARA CONCLUSÃO DO CURSO DE ENGENHARIA DE REDES DE COMUNICAÇÃO

BRASÍLIA/DF: JULHO - 2009 
UNIVERSIDADE DE BRASÍLIA

FACULDADE DE TECNOLOGIA

DEPARTAMENTO DE ENGENHARIA ELÉTRICA

\title{
CONVERGÊNCIA E INTEROPERABILIDADE ENTRE A REDE DE TELEFONIA FIXA COMUTADA E A REDE IP
}

\author{
FELIPE PÓVOA ARAÚJO \\ MARIA CECÍLIA DA COSTA BRAGA
}

MONOGRAFIA SUBMETIDA AO DEPARTAMENTO DE ENGENHARIA ELÉTRICA DA FACULDADE DE TECNOLOGIA DA UNIVERSIDADE DE BRASÍLIA COMO PARTE DOS REQUISITOS PARA A OBTENÇÃO DE GRAU DE ENGENHEIRO DE REDES DE COMUNICAÇÃO.

APROVADA POR:

FLÁVIO ELIAS GOMES DE DEUS, DOUTOR, UnB

(ORIENTADOR)

GEORGES AMVAME NZE, DOUTOR, UnB (EXAMINADOR INTERNO)

ALESSANDRO LUIZ CHAHINI ESCUDERO, ENGENHEIRO, CÂMARA DOS DEPUTADOS (EXAMINADOR EXTERNO) 


\section{FICHA CATALOGRÁFICA}

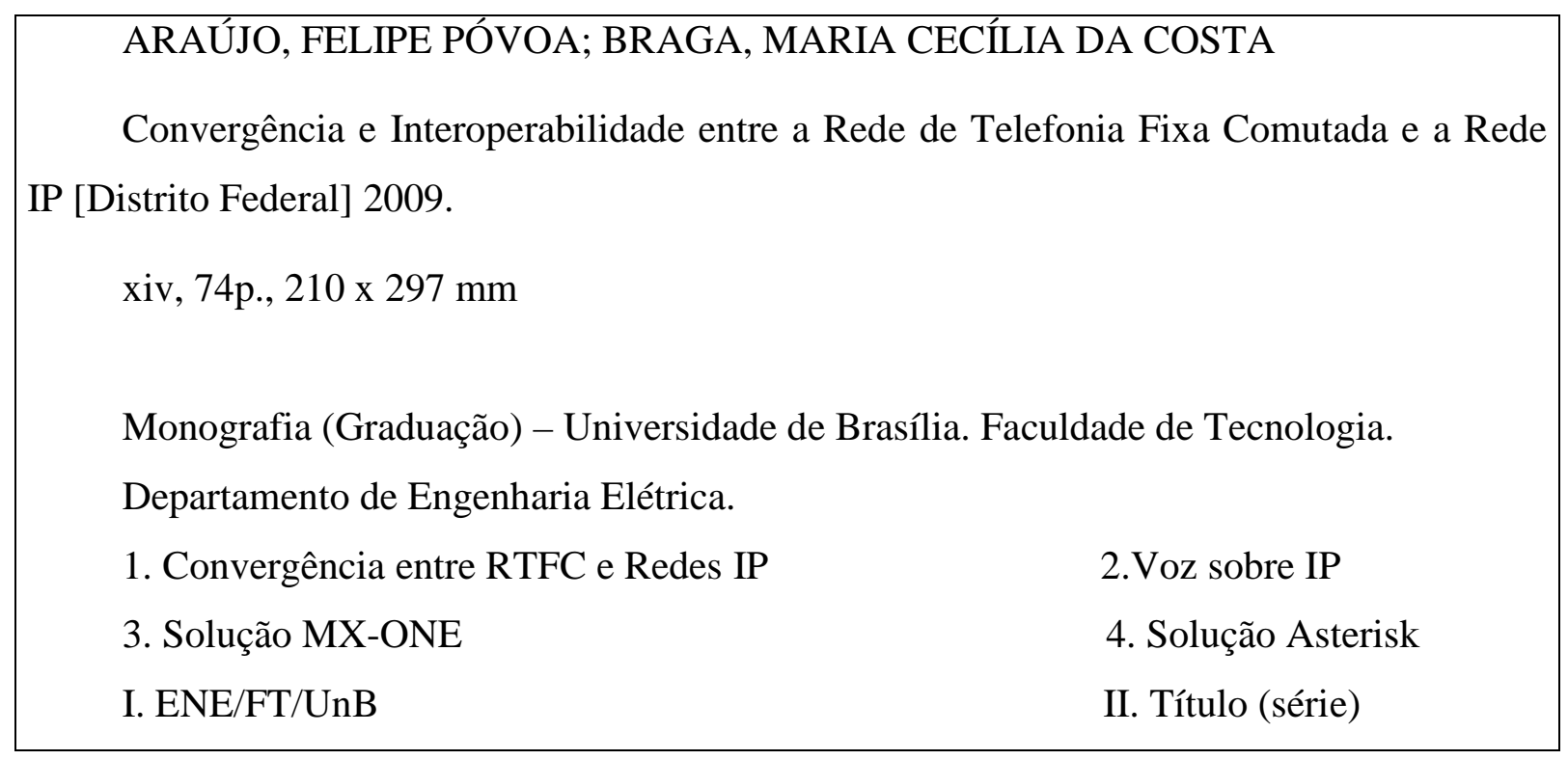

\section{REFERÊNCIA BIBLIOGRÁFICA}

ARAÚJO, F. P.; BRAGA, M. C. C. (2009). Convergência e Interoperabilidade entre a Rede de Telefonia Fixa Comutada e a Rede IP. Monografia de Graduação, Departamento de Engenharia Elétrica, Universidade de Brasília, Brasília, DF, 70p.

\section{CESSÃO DE DIREITOS}

AUTOR: Felipe Póvoa Araújo; Maria Cecília da Costa Braga.

TÍTULO: Convergência e Interoperabilidade entre a Rede de Telefonia Fixa Comutada e a Rede IP.

GRAU: Engenheiro de Redes de Comunicação $\quad$ ANO: 2009

É concedida à Universidade de Brasília permissão para reproduzir cópias desta monografia e para emprestar ou vender tais cópias somente para propósitos acadêmicos e científicos. O autor reserva outros direitos de publicação e nenhuma parte dessa monografia pode ser reproduzida sem autorização por escrito do autor.

Universidade de Brasília

Campus Universitário Darcy Ribeiro - Asa Norte

CEP 70.910.900 Brasília/DF - Brasil 


\section{AGRADECIMENTOS}

Agradecemos a Deus por estar sempre presente em nossas vidas, nos dando força e iluminando nosso caminho;

Aos nossos pais, que enfrentaram tantas dificuldades com o intuito de nos proporcionar boas condições de estudo, deixando outras coisas em segundo plano.

Aos nossos tios, primos e avós que mostraram sempre estar do nosso lado, nos apoiando para que concluíssemos mais essa etapa de nossas vidas;

Aos professores da UnB que ajudaram a nos dar uma boa base para o pleno desenvolvimento deste projeto;

Aos nossos amigos (e namorado), presentes em todas as horas que precisamos, nos ajudando a enfrentar as dificuldades, a aprender com os fracassos e a valorizar as conquistas;

A Wright que nos ajudou com as traduções na fase final do projeto;

Ao Alessandro, que nos indicou os caminhos a serem traçados para o bom desenvolvimento deste projeto.

Ao Arnon, Piau, Pelé, Daniel, Mavros, e demais funcionários da Câmara que nos deram todas as condições possíveis e sempre apoiaram o desenvolvimento deste projeto.

Enfim, a todos que, direta ou indiretamente, contribuíram para a nossa formação acadêmica com qualidade e para a conclusão deste trabalho. 


\section{RESUMO}

Este trabalho se enquadra na área de graduação em Engenharia de Redes de Comunicações e tem como objetivo descrever um modelo para a ampliação de uma central telefônica existente em um ambiente corporativo.

Essa ampliação tem como base a convergência entre a tecnologia da Rede de Telefonia Pública Comutada (RTPC) e a Rede de comutação por pacotes. Para alcançar o resultado esperado, de definir a melhor maneira e arquitetura para se realizar a ampliação, foram feitos estudos de conceitos sobre os dois tipos de rede citadas, como: infra-estrutura, sinalização, protocolos, segurança da informação trafegada, entre outros. Além disso, foram também estudados conceitos de voz sobre IP com o objetivo de entender melhor como funciona essa convergência entre a rede de voz e a rede de dados.

Em seguida, foram estudados conceitos sobre dois sistemas que funcionam como central telefônica. A partir do estudo inicial do sistema legado, foi possível definir as principais formas diferentes de se chegar a uma ampliação de forma transparente. Em seguida uma dessas maneiras foi escolhida como sendo a melhor forma de se implantar a ampliação do PABX pretendida. 


\begin{abstract}
This is a graduate project in Network Communication Engineering with the objective of describe a model for expansion of an existing telephone exchange in a corporate environment.

This amplification is based on the convergence between a Public Switched Telephone Network (PSTN) technology and a Packet Switching Network technology. To achieve the expected outcome, to define the best architecture for doing this expansion, studies were made of concepts on the two types of network such as infrastructure, signaling, protocols, security of information traffic, among others. Furthermore, we also studied concepts of Voice over IP in order to better understand how the convergence of the voice network and packet network.

Then concepts were studied on two systems that act as central telephone. From the initial study of the legacy system, it was possible to define the main ways to achieve an expansion in a transparent manner. Then one of those ways was chosen as the best way to deploy the extension of the PABX you want.
\end{abstract}




\section{LISTA DE FIGURA}

FIGURA 2.1 - CONFIGURAÇÃo BÁSICA DE UMA RTFC....................................................... 20

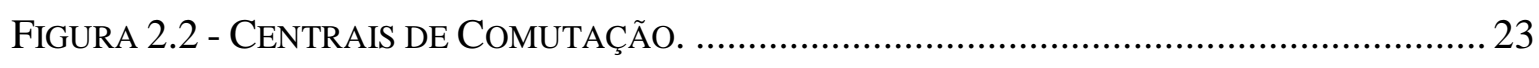

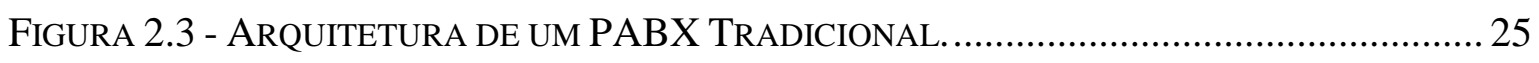

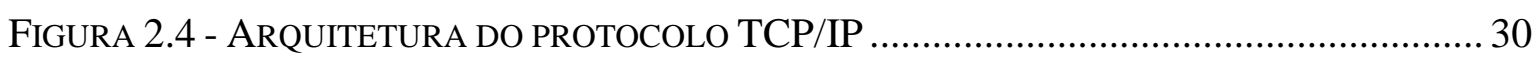

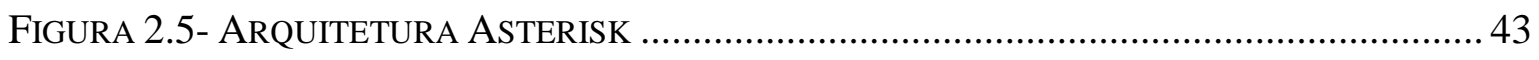

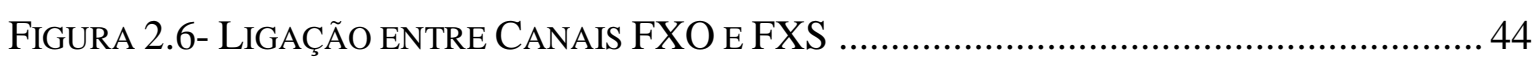

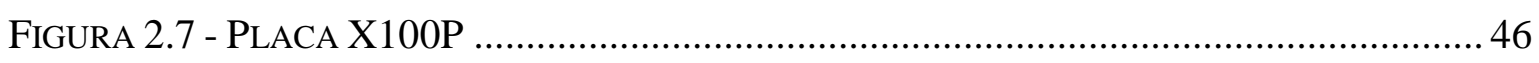

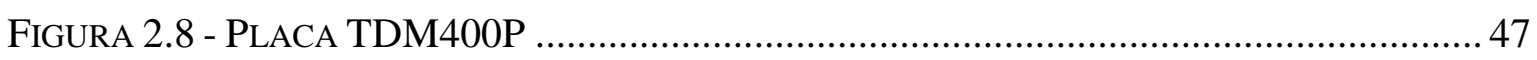

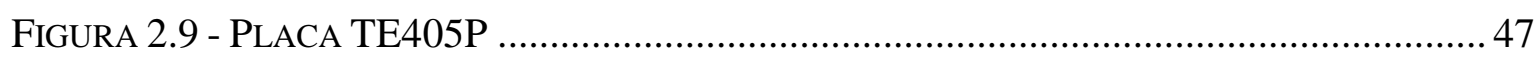

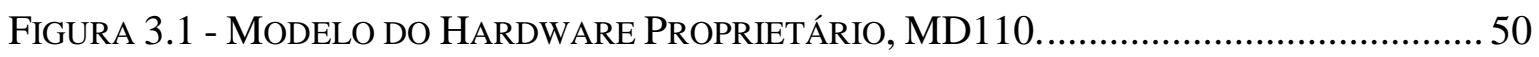

FIGURA 3.2 - REDE TELEFÔNICA DA CÂMARA DOS DEPUTADOS.......................................... 51

FigURA 4.1 - LIGAÇÃO ENTRE O PABX MD-110 E O MX-ONE .......................................... 58

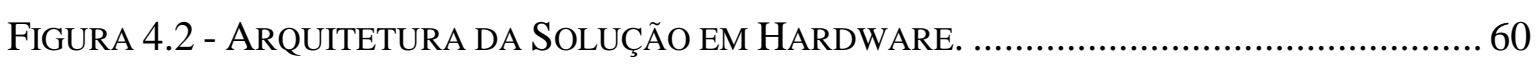

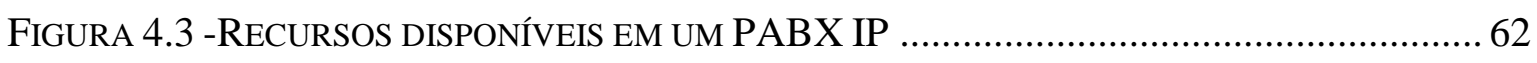

FIGURA 4.4 - REPRESENTAÇÃO DA INTEGRAÇÃO DOS RECURSOS DO PABX ASTERISK......... 62 Figura 4.5 - REPRESENTAÇÃo dA CENTRAL TElEFôNICA E REDE IP ATUAL DA CÂMARA doS

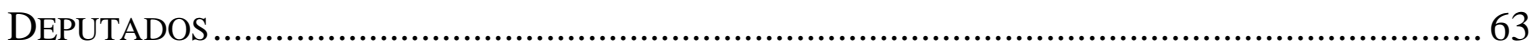

FIGURA 4.6 - CONVERGÊNCIA ENTRE REDES USANDO O ASTERISK ....................................... 65 


\section{LISTA DE TABELAS}

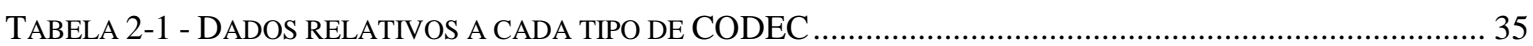

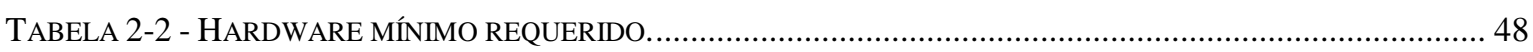

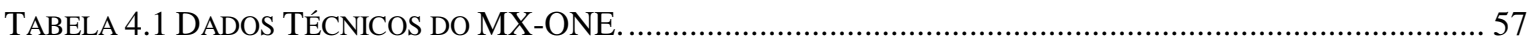




\section{LISTA DE ACRÔNIMOS}

\begin{tabular}{|c|c|}
\hline AES & Advanced Encryption Standart \\
\hline ARPANET & Advanced Research Projects Agency Network \\
\hline CENIN & Centro de informática \\
\hline CODECs & Coder/Decoder \\
\hline $\mathrm{CPU}$ & Central Processing Unit \\
\hline DAC & Distribuidor Automático de Chamadas \\
\hline DARPA & Defense Advanced Research Projects Agency \\
\hline DEA & Data Encryption Algorithm \\
\hline DES & Data Encryption Standart \\
\hline DSA & Digital Signature Algorithm \\
\hline DSP & Digital Signal Processing \\
\hline ERB & Estação Rádio Base \\
\hline ESU & Embedded Server Unit \\
\hline $\mathrm{FXO}$ & Foreing Exchange Station \\
\hline FXS & Foreing Exchange Office \\
\hline GoS & Grade of Service \\
\hline GPL & General Public License \\
\hline HTTP & Hyper Text Transmission Protocol \\
\hline IDEA & International Data Encryption Algorithm \\
\hline IAX & Inter-Asterisk Exchange Protocol \\
\hline IP & Internet Protocol \\
\hline IPSec & IP Security \\
\hline ISDN & Integrated Services Digital Network \\
\hline ISO & International Organization Standardization \\
\hline ITU & International Telecommunication Union \\
\hline MEGACO & Media Gateway Control Protocol \\
\hline MGCP & Media Gateway and Control Protocol \\
\hline MOS & Mean Opinion Score \\
\hline NAT & Network Address Translation \\
\hline OSI & Open System Interconnection \\
\hline PABX & Private Automatic Branch Exchange \\
\hline
\end{tabular}




\begin{tabular}{|c|c|}
\hline PBX & Private Branch Exchange \\
\hline PGP & Pretty Good Privacy \\
\hline PPTP & Point-to-point tunneling protocol \\
\hline PSS1 & Private Signaling System Number1 \\
\hline PCM & Pulse Code Modulation \\
\hline Q-SIG & Sinalização-Q \\
\hline Q-SIG BC & Q-SIG Basic Call \\
\hline Q-SIG GF & Q-SIG Generic Function \\
\hline QoS & Quality of Service \\
\hline RC5 & Rivest Cipher 5 \\
\hline RTP & Real Time Protocol \\
\hline RTCP & Real Time Control Protocol \\
\hline RTSP & Real-time Streaming Protocol \\
\hline RTFC & Rede de Telefonia Fixa Comutada \\
\hline SDP & Session Description Protocol \\
\hline Siafi & Sistema Integrado de Administração Financeira \\
\hline SIGTRAN & Signalling Transport \\
\hline SIP & Session Initiation Protocol \\
\hline SMTP & Simple Mail Transfer Protocol \\
\hline SS7 & Sinalização por Canal Comum Número 7 \\
\hline SSL & Secure Socket Layer \\
\hline STFC & Serviço Telefônico Fixo Comutado \\
\hline TCP & Transmission Control Protocol \\
\hline TCP/IP & Transfer Control Protocol/Internet Protocol \\
\hline TLS & Transport Layer Security \\
\hline TUP & Terminais de Uso Público \\
\hline UA & User Agent \\
\hline UAC & User Agent Client \\
\hline UAS & User Agent Server \\
\hline UDP & User Datagrama Protocol \\
\hline URA & Unidade de Resposta Automática \\
\hline VoIP & Voz sobre IP. \\
\hline VPN & Virtual Private Network \\
\hline
\end{tabular}


WiMAX Worldwide Interoperability for Microwave Access

WLL Wireless Local Loop 


\section{SUMÁRIO}

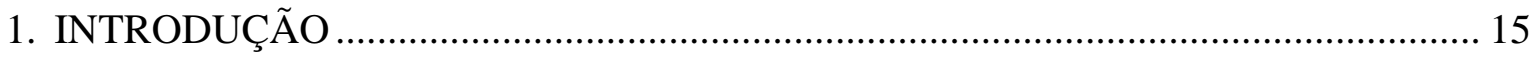

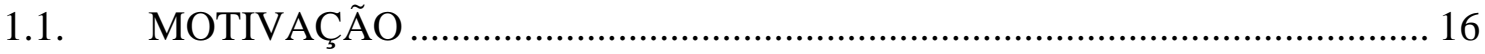

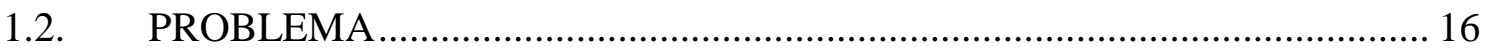

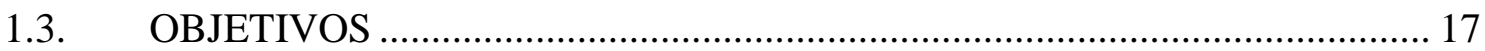

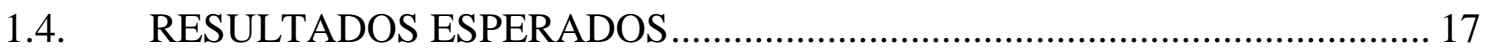

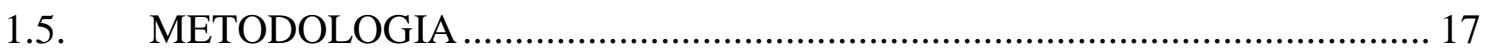

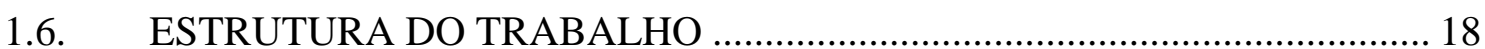

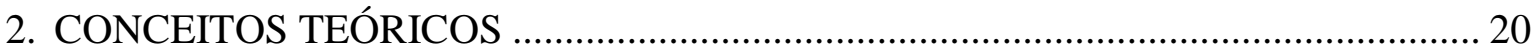

2.1. REDE DE TELEFONIA FIXA COMUTADA …......................................... 20

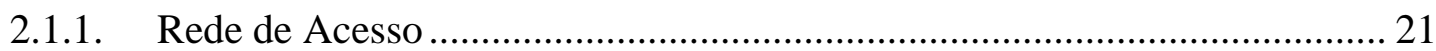

2.1.2. Rede de Comutação .................................................................................. 21

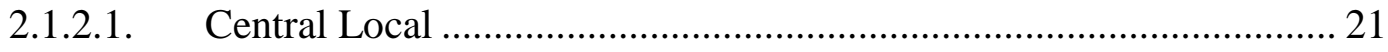

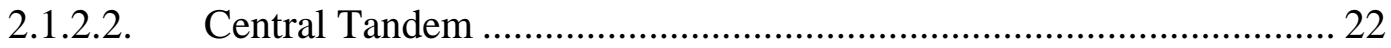

2.1.2.3. Central Trânsito e Central Trânsito Internacional ............................... 22

2.1.2.4. Rede de Transmissão .......................................................................... 22

2.1.3. Sinalização por Canal Comum Número 7 ................................................ 23

2.1.4. Centrais Privadas de Comutação Telefônica ............................................... 24

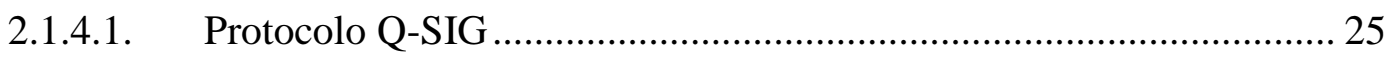

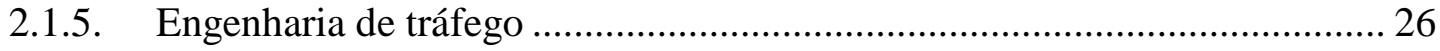

2.2. REDE DE COMUTAÇÃO DE PACOTES .................................................... 27

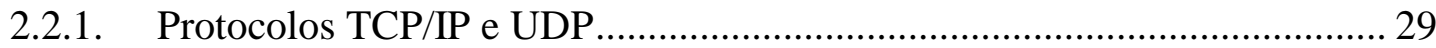

2.2.1.1. Camada de Aplicativos ...................................................................... 31

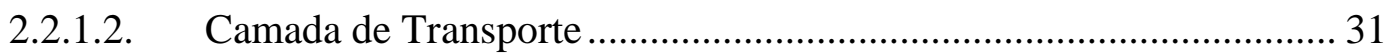

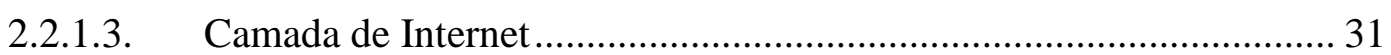

2.2.1.4. Camada de Interface de Rede ......................................................... 32

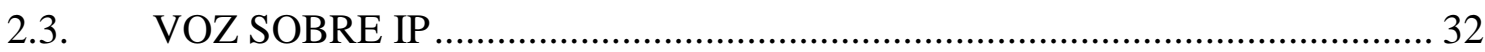




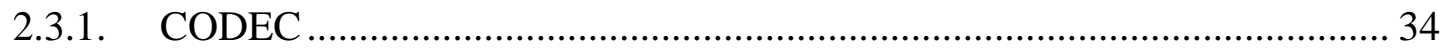

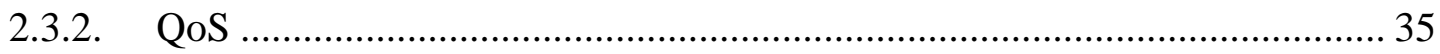

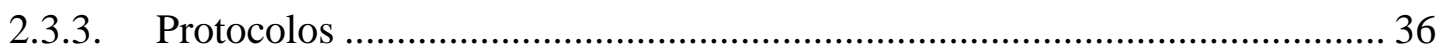

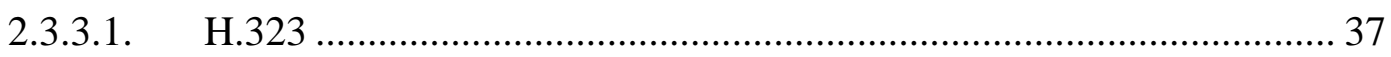

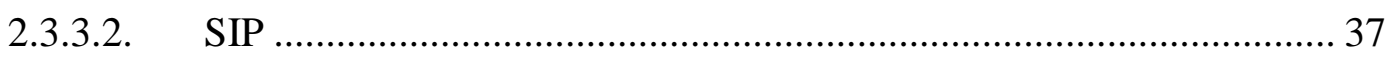

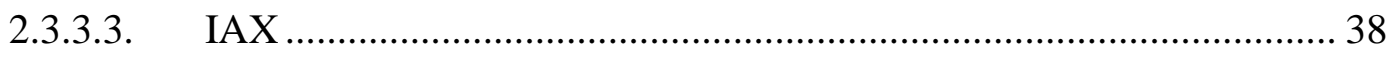

2.4. SEGURANÇA DA INFORMAÇÃO ........................................................... 39

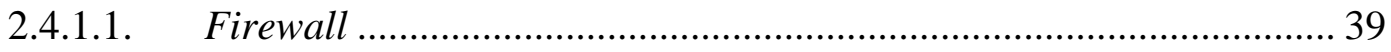

2.4.1.2. Criptografia.................................................................................... 40

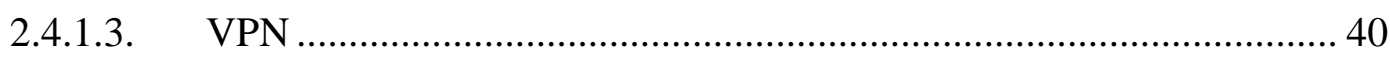

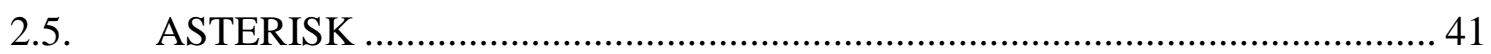

2.5.1. Arquitetura do Asterisk ........................................................................ 43

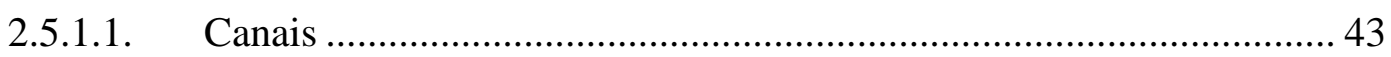

2.5.1.2. Protocolos Asterisk ............................................................................. 44

2.5.1.3. CODECs Asterisk........................................................................ 45

2.5.1.4. Aplicações do Asterisk ....................................................................... 45

2.5.1.5. Hardware de Telefonia para o Asterisk ............................................... 46

2.5.1.6. Hardware Mínimo Requerido ............................................................. 47

2.5.1.7. Sistema Operacional ...................................................................... 48

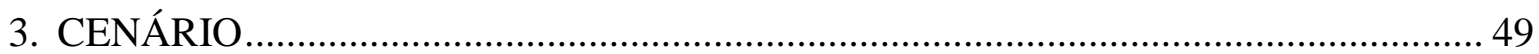

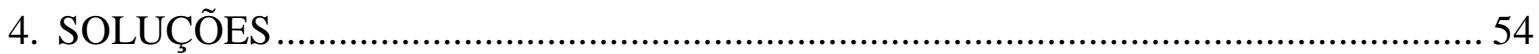

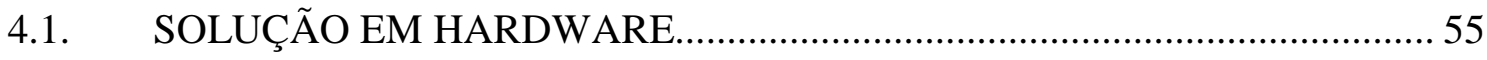

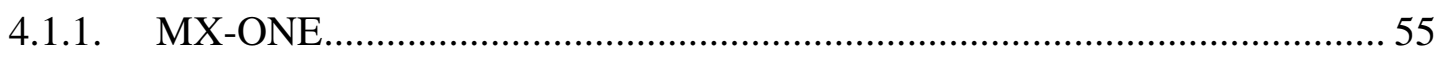

4.1.2. A SOLUÇÃO SUGERIDA...................................................................... 57

4.2. SOLUÇÃO EM SOFTWARE LIVRE …………………………………….... 61

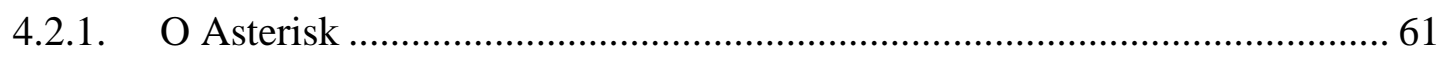

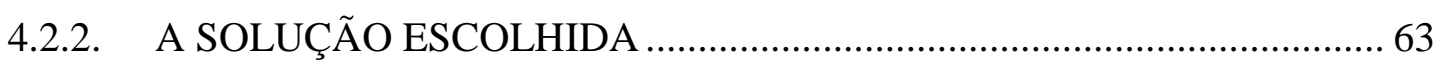

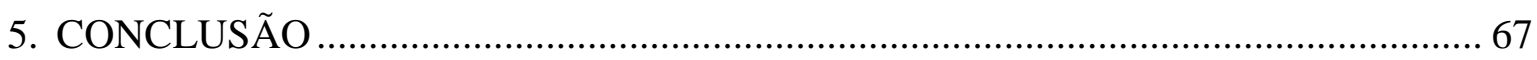

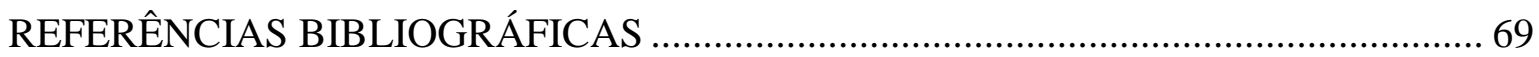

xiii 
ANEXO A - Tabela Erlang B

.71 


\section{INTRODUÇÃO}

O sistema de telefonia padrão advém do século XIX com o surgimento das primeiras redes telefônicas. Desde então, este sistema foi evoluindo até chegar às atuais centrais telefônicas digitais [Soares 2008]. Apesar desta evolução, o sistema de telefonia convencional ainda apresenta algumas desvantagens com relação à utilização dos seus recursos, uma vez que o sistema é baseado em circuitos dedicados.

Por este motivo e também pelo crescente uso da Internet, procurou-se fazer uma rede única que fosse capaz de transmitir dados e voz através de uma única infra-estrutura de telecomunicações. A idéia dessa convergência apresenta várias vantagens, como o melhor aproveitamento dos recursos de telecomunicações existentes, possibilitando a transmissão de voz, vídeos e dados através da mesma infra-estrutura, barateando, assim, os serviços de telecomunicações.

As redes de telefonia convencionais foram desenvolvidas inicialmente para trafegar exclusivamente voz, enquanto as redes de dados são mais versáteis, suportando o transporte de outros tipos de informação. Protocolos como o SS7 (Sinalização por Canal Comum Número 7) [Davidson 2000], utilizado para a sinalização das chamadas na rede de telefonia pública, estão sendo substituídos por protocolos como o SIGTRAN (Signalling Transport) [IEC2 005] (SS7 sobre IP), H.323 e SIP (Session Initiation Protocol), que funcionam em redes TCP/IP (Transfer Control Protocol/Internet Protocol) [Davidson 2000]. Além disso, sistemas proprietários que rodam as aplicações PBX (Private Branch Exchange) estão sendo substituídos por aplicações que rodam em sistemas operacionais conhecidos, como o Windows e o Linux.

Com o intuito de desenvolver um sistema capaz de manter as funcionalidades do atual sistema legado e fazer a convergência entre a rede de telefonia e a rede de dados, seguindo as principais tendências de mercado [Walsh 2005], foi proposto um upgrade da atual central telefônica de uma instituição utilizando a tecnologia de Voz sobre IP - VoIP. 


\subsection{MOTIVAÇÃ̃}

O projeto VoIP em instituições públicas vem se mostrando, a cada dia, ser de fundamental importância para a evolução constante dos sistemas de telecomunicações a elas pertencentes. Um estudo realizado pela Infonetics Research aponta que o crescimento de tecnologias VoIP se deve, principalmente, à adesão de grandes empresas, das quais, no ano de 2006, cerca de $36 \%$ já utilizavam essa tecnologia. Nas pequenas empresas a adesão era de cerca de 15\% com expectativa para que esse percentual seja triplicado até 2010 [Greene 2006].

No Brasil, as instituições públicas vêm adotando o uso dessa tecnologia para cortar gastos com telefonia. Dados obtidos no Sistema Integrado de Administração Financeira do Governo Federal (Siafi) mostram que a união gasta mais de $\mathrm{R} \$ 700$ milhões por ano com telefonia. Esses custos poderiam ser reduzidos fortemente com o uso da tecnologia VoIP. Em matéria publicada pelo jornal O Globo, o Ministro das Comunicações, Hélio Costa, informou que pretende propor ao presidente Luis Inácio Lula da Silva a adoção de sistemas de voz sobre IP para, segundo ele, reduzir até 50\% os gastos com telefonia da União [Tavares 2007]. Em Brasília, já foi implantada uma infovia que liga todos os ministérios com o intuito de zerar os custos com ligações entre os mesmos. A tendência, então, é que as instituições públicas venham a adotar cada vez mais o uso dessa tecnologia para baratear os custos com telefonia.

A motivação deste trabalho se baseia em alguns pontos importantes. $\mathrm{O}$ assunto é muito importante no mercado de trabalho moderno. As comunicações por voz sempre foram chaves nos contatos entre instituições e, por isso, deve ser estudado. A constante evolução que esta tecnologia sofre acaba fomentando mais o desenvolvimento de estudos nesta área, já que é um assunto pouco estudado academicamente.

\subsection{PROBLEMA}

No cenário proposto, encontramos uma necessidade de migrar o sistema para um sistema baseado em aplicações IP. Esta migração possibilitaria uma nova gama de recursos e possibilidades de desenvolvimento de novas facilidades para o sistema de comunicação. Além disso, era importante manter o sistema atualmente presente. Os altos investimentos iniciais 
para implantação do atual sistema não permite que este seja descartado neste processo de migração. O sistema legado deve se manter operante e, de forma completamente transparente, deve interagir com a ampliação a ser feita na centra.

O problema de custo deve ser levado em conta também. A atual conjuntura financeira que o mundo passa, leva a uma necessidade de sempre se gastar o mínimo possível para se fazer determinada coisa. No caso do cenário proposto, este fator deve ser levado em conta com o intuito de minimizar não só os custos iniciais com a migração, mas também os futuros custos operacionais.

\subsection{OBJETIVOS}

O objetivo deste trabalho é, então, desenvolver distintas soluções para a integração do sistema atual com o novo sistema ampliado. A migração pro mundo IP se daria através de uma ampliação da central existente. Por isso, é necessário desenvolver diferentes maneiras de se fazer esta ampliação.

Após a delimitação de diferentes soluções, deve ser definida a melhor maneira de fazer esta convergência para manter uma interoperabilidade transparente para ambos os sistemas. Este é o objetivo principal deste trabalho.

\subsection{RESULTADOS ESPERADOS}

Por fim, pretende-se indicar um modelo de integração que melhor se adéquie à realidade da instituição.

\subsection{METODOLOGIA}

Para alcançar os objetivos traçados, algumas metodologias foram trilhadas. Primeiramente foi feito um estudo teórico acerca do assunto. Esta revisão de literatura é de 
fundamental importância para o bom desenvolvimento de todo e qualquer trabalho acadêmico.

Em seguida foi feito um estudo técnico da central telefônica do cenário em questão. Com o estudo do PABX instalado na instituição, foi possível entender melhor o problema e traçar os melhores caminhos a se seguir para alcançar a convergência proposta.

Uma pesquisa de campo foi feita para se saber quais os verdadeiros requisitos do sistema ampliado. Para isso foram feitas pesquisas com pessoal e uma análise do tráfego a ser ofertado pelo sistema ampliado.

Após essas etapas e concluídos os objetivos, a apresentação da solução indicada foi feita para expor os caminhos e as características que cada tipo de solução traz.

\subsection{ESTRUTURA DO TRABALHO}

A estrutura do trabalho foi dividida em 5 (cinco) capítulos. No capítulo 1 (um) foi feita uma introdução contendo uma breve revisão teórica dos sistemas de telefonia, bem como a descrição do problema a ser resolvido, traçando os objetivos principais deste trabalho. Para que seja realizado o estudo em questão é necessário que inicialmente se tenha o conhecimento básico necessário dos principais protocolos e estruturas de redes que compõem o cenário em questão. Além disso, é necessário o entendimento de alguns conceitos presentes na tecnologia VoIP para melhor entendê-la. Essa revisão teórica é feita no capítulo 2 (dois).

No capitulo 3 (três) é feita a descrição do cenário proposto. Neste capítulo é mostrada a arquitetura do sistema presente atualmente na Câmara dos Deputados. O tipo de equipamento, as demandas de tráfego, dentre outras características importantes para o pleno desenvolvimento do trabalho.

No capítulo 4 (quatro) são apresentadas as soluções possíveis para o sistema em questão. Neste capítulo são apresentados os dois tipos básicos de soluções: uma solução em Hardware, utilizando um equipamento do mesmo fabricante do atual sistema da instituição, e uma solução alternativa baseada em software, utilizando um software livre que desempenha a função de um PABX (Private Automatic Branch Exchange) usando a rede IP (Internet Protocol) para prover os serviços requeridos. Nesta última, foi utilizado o software Asterisk, 
por este ser muito estudado internacionalmente e constantemente utilizado nestas situações. Por fim, são feitas comparações entre os dois tipos de soluções.

Para finalizar o trabalho, no capítulo 5 é apontada a solução considerada como sento a que melhor se encaixa ao cenário proposto. Além disso são feitas as considerações finais do trabalho estudado. 


\section{CONCEITOS TEÓRICOS}

Nessa seção será apresentada uma breve descrição dos temas estudados no trabalho para auxiliar no estudo de uma solução para uma possível ampliação de uma Central Telefônica Privada. São eles: Rede de Telefonia Fixa Comutada (RTFC), Rede de Comutação de Pacotes, Voz sobre IP (VoIP), Segurança da Informação e o software Asterisk.

\subsection{REDE DE TELEFONIA FIXA COMUTADA}

A Rede de Telefonia Fixa Comutada (RTFC) surgiu da necessidade de se criar um sistema que suportaria a transmissão de voz em longas distâncias. A RTFC corresponde basicamente a Centrais Telefônicas ligadas entre si e também a terminais telefônicos pertencente a usuários (assinante) [Colcher 2005], seja ele um usuário comum ou mesmo um usuário pertencente a um PABX.

A Figura 2.1 representa uma configuração básica de uma Rede de Telefonia Fixa Comutada:

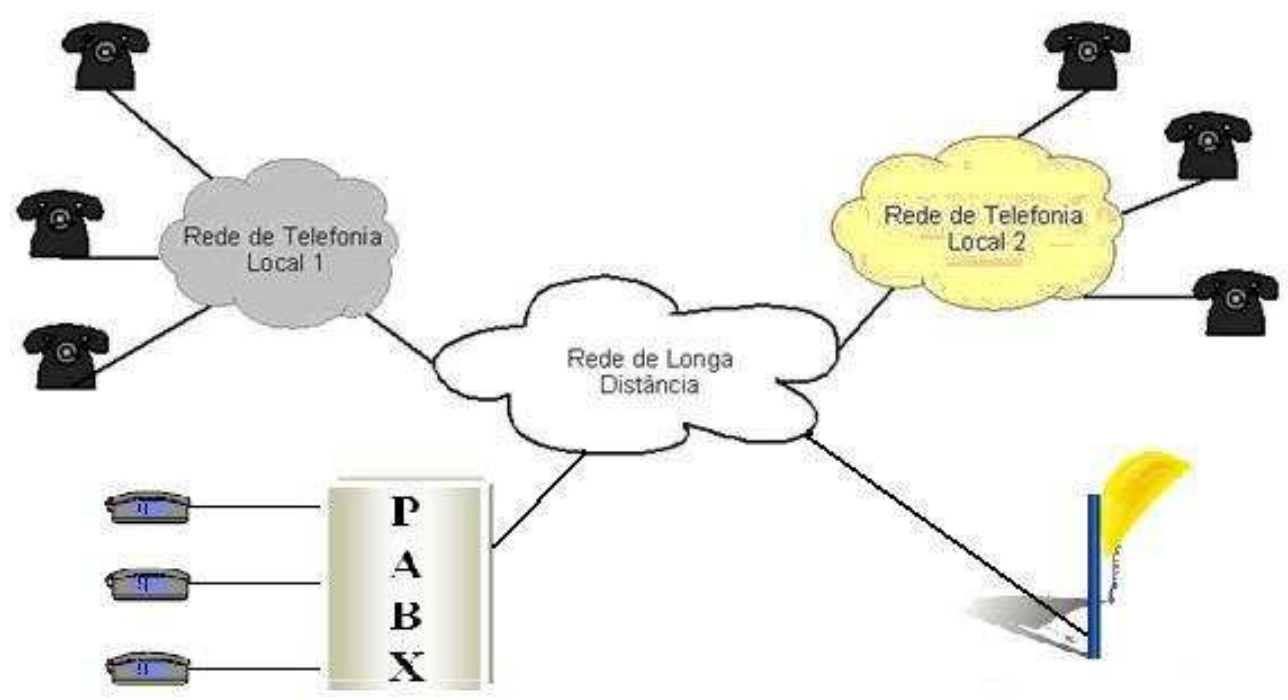

Figura 2.1 - Configuração Básica de uma RTFC Fonte: [Modificado de Silva 2008] 


\subsection{1. $\quad$ Rede de Acesso}

A Rede de Acesso é um subsistema da Rede de Telefonia Fixa. Ela interliga todos os usuários - assinantes convencionais, coorporativos (PABX) e Terminais de Uso Público (TUP) - à Central Telefônica. É formada por linhas telefônicas (acessos), isto é, um par de cabos de fios metálicos ou fibra óptica para cada um dos usuários [Jeszensky 2003].

Existe ainda uma técnica mais recente de acesso através de uma rede sem fio, onde são utilizados aspectos parecidos com os do Sistema de Celular. Nessa técnica a Central Telefônica se liga a uma Estação Rádio Base (ERB) e essa, por sua vez, transmite a informação para o usuário através de um terminal com suporte para um acesso sem fio. $\mathrm{O}$ sistema usado nesse tipo de acesso é o Wireless Local Loop (WLL), que pode fornecer comunicação entre localidades em um raio de cerca de $50 \mathrm{~km}$ no caso do Worldwide Interoperability for Microwave Access, WiMAX, por exemplo [Prado 2006].

\subsubsection{Rede de Comutação}

É um segundo subsistema pertencente à Rede de Telefonia Fixa de Comutação. A ela pertencem os equipamentos que irão definir os caminhos utilizados para possibilitar a comunicação entre os usuários. É composta por elementos de Redes chamados de Centrais de Comutação. Essas Centrais de Comutação estão representadas na Figura 2.2 e descritas a seguir.

\subsubsection{Central Local}

Central que possui conexão direta com os assinantes. Ela pode se ligar a outras Centrais Locais através de Centrais Tandem, ou por conexões diretas, através de troncos. O número pertencente ao assinante é composto por um prefixo indicativo da Central Local, geralmente os quatro primeiros dígitos do telefone, e uma parte que representa cada terminal de assinante, os quatro últimos. Quando se deseja fazer ligações para fora da região local, como, por exemplo, chamada nacional ou internacional, é necessário digitar códigos adicionais - 
códigos de área internacional, código de área nacional e código de prestadora de serviço de longa distância [ANATEL 1998].

\subsubsection{Central Tandem}

Em certas regiões, principalmente as de grande crescimento urbano, são construídas Centrais Tandem, que ligam as Centrais Locais às Centrais de Trânsito. Esse tipo de recurso é usado para otimizar o encaminhamento das chamadas telefônicas. Essas Centrais podem ser comparadas às Centrais de Trânsito quando se trata do aspecto de interligar centrais de comutação entre si. Existem ainda Centrais que desempenham a função tanto de Central Local como de Central Tandem. São as chamadas Centrais Mistas.

\subsubsection{Central Trânsito e Central Trânsito Internacional}

Centrais que não possuem ligação direta com os terminais do assinante. São organizadas hierarquicamente de forma que a Central de Trânsito Internacional é a de mais alta hierarquia e comuta as chamadas entre diferentes países, já a Central de Trânsito comuta chamadas originadas em locais relativamente mais próximos, como, por exemplo, cidades e estados [Jeszensky 2003].

\subsubsection{Rede de Transmissão}

É a rede composta de sistemas de transmissão, que podem ser físicos ou não, como, por exemplo, cabos coaxiais e fibras ópticas ou o espaço livre, por onde são realizadas interconexões entre centrais de comutação através de enlaces de microondas, por exemplo [Rappaport 2002]. O meio de transmissão é composto por toda a estrutura que participa do transporte das informações entre a central de origem da chamada até a central em que se encontra o assinante de destino. Como exemplo dos equipamentos da estrutura pode-se citar: 
telefone, linha de assinante, percurso dentro da central telefônica, linhas físicas, rádio, entre outros.

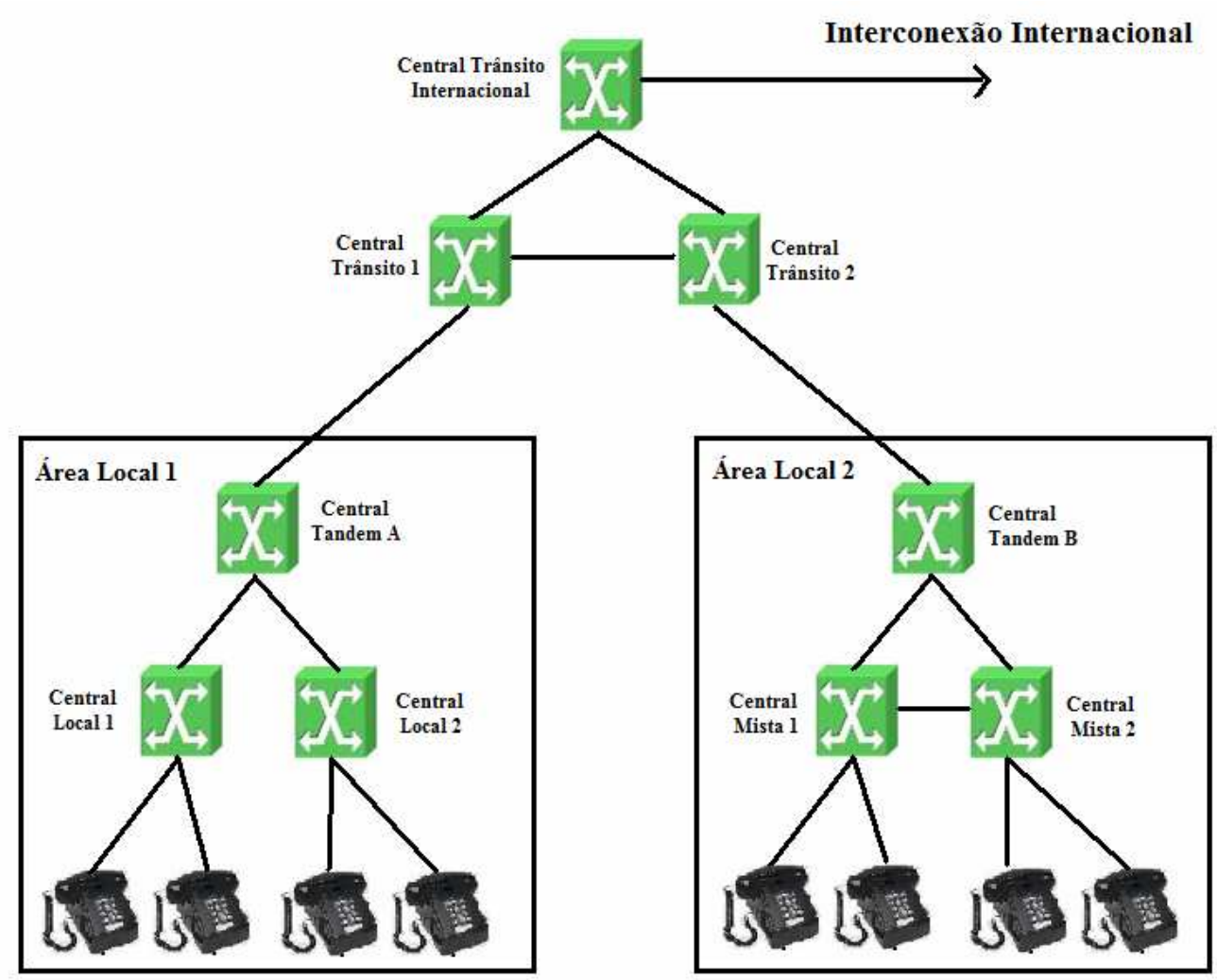

Figura 2.2 - Centrais de Comutação.

\subsubsection{Sinalização por Canal Comum Número 7}

Além dos subsistemas descritos acima existe outro tipo de subsistema responsável pela inteligência de comunicação entre os elementos da rede de telecomunicações. É um tipo de sistema usado na telefonia que reserva um canal por onde irá trafegar somente informações relativas à sinalização para a realização de chamadas, isto é, dentre os canais disponíveis em um tronco, destina-se um canal exclusivamente para transmissão de sinalização.

As informações que trafegam por esse canal são basicamente sinais que permitirão o estabelecimento da conexão, sinais de controle e gerência da rede e dados sobre a tarifação. Todos esses dados são transmitidos de acordo com protocolos padronizados pelo International Telecommunication Union, ITU [Colcher 2005]. 
Entre as vantagens que o sistema possui, podemos apontar:

- $\quad$ O tempo de estabelecimento de chamada é reduzido, já que a sinalização passa a não interferir intrinsecamente no canal de conversação;

- Diminui as possibilidades de fraude já que o usuário não tem acesso ao canal de sinalização;

- $\quad$ Os sinais trafegam de maneira mais rápida (pouco delay);

- $\quad$ Constitui ferramenta que introduz redundância para detecção e correção de erros;

\subsubsection{Centrais Privadas de Comutação Telefônica}

Com a constante evolução dos sistemas de comunicações, a necessidade de se ter um meio viável e eficaz de manter contato com clientes e filiais fez com que a tecnologia para a telefonia privada se desenvolvesse ao longo dos últimos anos. Na década de 80 surgiu a idéia de um Private Branch Exchange, PBX, e em seguida o Private Automatic Branch Exchange, PABX. Se tratando na prática de uma central telefônica privada, os PABX's eram inicialmente muito limitados tanto em relação aos computadores quanto aos microprocessadores, não havendo sequer uma rede de dados sólida ainda [Sato 2004].

Tradicionalmente, a arquitetura de um PABX tem a estrutura apresentada na Figura 2.3. O controlador de processo executa o software de comunicação, responsável por todas as funcionalidades do sistema. Os dispositivos de ponta são os ramais utilizados pelos usuários finais. Existem basicamente dois tipos de dispositivos: os ramais digitais e os ramais analógicos. Os módulos são responsáveis pela ligação do PABX com o Serviço Telefônico Fixo Comutado, STFC, além de servir de interface entre os dispositivos de ponta e a central em si. O módulo de interconexão permite a interconexão de portas de diferentes módulos.

Com o desenvolvimento tecnológico nos últimos anos, surgiram novas aplicações e novos tipos de dispositivos de ponta. Dentre eles, destacam-se os ramais IP e os ramais móveis. Estes utilizam uma rede sem fio para acessar a central telefônica. Aqueles utilizam a própria rede estruturada de internet para acessar o PABX [Sato 2004]. 


\section{Arquitetura de um PABX Tradicional}

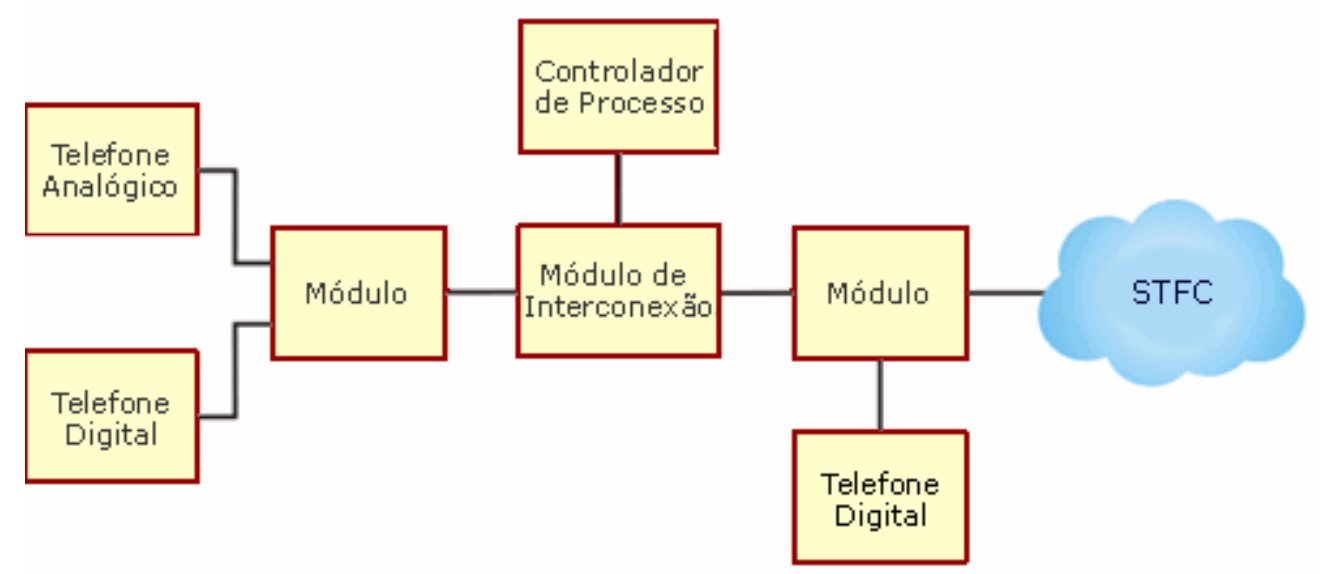

Figura 2.3 - Arquitetura de um PABX Tradicional. Fonte: [Sato 2004]

\subsubsection{Protocolo Q-SIG}

O Q-SIG (Sinalização-Q), conhecido internacionalmente pelo nome de Private Signaling System Numberl (PSS1), é um sistema de sinalização que interliga as mais diversas redes corporativas [Davidson 2000]. Algumas das características do sistema de sinalização global Q-SIG são:

- $\quad$ Seus padrões permitem a interconexão de equipamentos dos mais diversos fornecedores;

- $\quad$ Permite a que haja operações entre PBXs para serviços básicos, transparência para facilidades e para serviços suplementares;

- Opera entre redes ISDN (Integrated Services Digital Network) públicas e privadas;

- Além da compatibilidade com vários tipos de PBX, pode também operar com qualquer topologia de rede desejada;

- $\quad$ Não possui restrições em relação aos planos de numeração privados;

O protocolo suporta vários tipos de serviços para redes PBX corporativas. Entre eles, estão os três principais que são [Davidson 2000]: Serviço básico (Q-SIG BC - Basic Call) que fornece capacidade de estabelecer, gerenciar e finalizar uma chamada. Alguns exemplos desse serviço incluem voz, áudio $3.1 \mathrm{kHz}$ e $64 \mathrm{kbps}$ não restrito. O segundo serviço é o 
chamado Q-SIG GF - Generic Function, que é um método padronizado para o transporte de facilidades não padronizadas, trazendo assim, transparência para facilidades implantadas. $\mathrm{O}$ serviço permite a troca de informações de sinalização para controle de facilidades adicionais e suplementares de rede sobre redes corporativas. E terceiro são os serviços suplementares, que inclui os serviços e facilidades adicionais de rede, que funcionam completando, identificando, transferindo e dando seguimento a chamadas, além de chamada em espera e aviso de cobrança.

\subsubsection{Engenharia de tráfego}

Em sistemas de comunicações existe um determinado número de usuários e um determinado número de troncos, que possibilita realizar ligações através de seus canais. Um tronco pode ser constituído de vários canais. No caso de um enlace E1, por exemplo, existem 32 canais de comunicação, sendo 30 canais para transmissão da informação desejada e 2 para sinalização e controle. Uma das principais características dos sistemas de comunicações é que nem todos os usuários estão efetuando ou recebendo ligações ao mesmo tempo. Um dos principais preceitos em engenharia de telecomunicações é determinar o número de troncos requeridos em uma rota ou comunicação entre duas centrais telefônicas; fixas ou móveis para prover certo Grau de Serviço (GoS, do inglês Grade of Service) [Garg 2006]. Grau de serviço é uma espécie de medida de qualidade de rede. Nada mais é que uma probabilidade de bloqueio, dado um número de canais existentes e demanda de tráfego requerido.

O conceito de tráfego surge da idéia de tempo cursado por tempo disponível (Erlang). Por exemplo, se no intervalo de uma hora de conversa, um usuário utiliza o canal durante todo o tempo temos: $\mathrm{A}=1$ (tempo utilizado)/1 (tempo disponível), o que leva a um tráfego de 1 Erlang. Na prática, cada usuário usa durante pouco tempo um determinado canal, o que possibilita um sistema de múltiplo acesso de todos os usuários a um número reduzido de canais.

Na teoria de tráfego telefônico, se aceita que a chegada ou demanda por serviço ou canal obedece a uma distribuição de Poisson; os tempos de retenção de um canal seguem uma distribuição exponencial e para a maioria dos casos, o bloqueio de chamadas por falta de canais gera perda de chamada. Um bloqueio de chamada vai ocorrer sempre que um usuário tentar acessar um canal e não tiver canal disponível naquele momento. É possível modelar os 
eventos de chegada, saída e retenção de acordo com uma cadeia de Markov, com nascimentos e mortes [Yacoub 1993].

Em 1908, Agner Karup Erlang, funcionário de uma companhia telefônica desenvolveu uma fórmula para solucionar os problemas da quantidade de canais necessários para interconexão entre duas centrais. Esta fórmula, conhecida como Erlang B é apresentada na Equação 2.1.5.1, onde A representa o tráfego oferecido, $\mathrm{N}$ o número de canais para escoar o tráfego e $P_{b}$ é a probabilidade de bloqueio.

$$
P_{b}=\frac{\frac{A^{N}}{N !}}{\sum_{i=0}^{N} \frac{A^{i}}{i !}}
$$

Para reduzir a dificuldade em realizar os cálculos com esta fórmula, foram elaboradas tabelas, onde, dado o bloqueio e o número de canais, se obtém o tráfego suportado. Estas tabelas, conhecidas como tabelas de Erlang são apresentadas no Anexo A.

\subsection{REDE DE COMUTAÇÃO DE PACOTES}

Originalmente desenvolvidas para o tráfego de voz, as redes de telecomunicações tinham por característica o uso exclusivo dos canais por cada usuário. As chamadas redes dedicadas ainda compõem boa parte do sistema telefônico atual, no qual um canal de 64Kbps é alocado temporária e exclusivamente para um usuário durante uma ligação.

Quando se trata de transporte de voz, o tipo de sistema descrito acima é bastante eficiente, principalmente porque em uma chamada como essa os usuários tendem a manter um alto nível de conversação durante todo o tempo. Em uma chamada, a conectividade é mantida continuamente e dedicada exclusivamente a essas chamadas, independentemente de a vocalização estar ativa ou não [Soares 2008].

Mas quando se trata de transporte de dados, esse tipo de sistema apresenta um grande desperdício de largura de banda por existir uma extensa variação do tráfego de dados ao longo do tempo, o que minimiza a taxa de ocupação de um canal. O circuito dedicado é, então, 
ineficiente para o tráfego de dados e surge a necessidade de se otimizar essa ocupação de canal para minimizar os custos com a rede física [Soares 2008].

A Comutação de pacotes é uma técnica de transmissão de mensagens que são fragmentadas em unidades menores, chamadas de pacotes, e enviadas pela rede. Inicialmente, cada host desse novo tipo de rede teria seu próprio roteador. Nesse protótipo, cada nó tem como filosofia a conexão com mais de um ponto, sendo que no caso de queda de uma conexão, caminhos alternativos podem ser encontrados para a comunicação. A construção desse protótipo resultou em uma rede denominada ARPANET (Advanced Research Projects Agency Network), considerada, hoje, a primeira rede de comutação de pacotes e a predecessora da internet [Soares 2008].

Os pacotes se deslocam pela rede de nó a nó, ao contrário do deslocamento fim a fim da comutação por circuito. Esses nós são formados por elementos de redes, chamados de roteadores, cada um deles possui tabelas com as rotas que podem ser seguidas e as informações sobre elas. Como cada pacote pode individualmente percorrer diferentes rotas, é comum haver um atraso em relação aos diferentes pacotes que compõem a mensagem, ou até mesmo esses pacotes chegarem em uma seqüência diferente da que foram enviados, e é por isso, que ao chegar ao destinatário, os pacotes recebem um tratamento de reconstrução da mensagem original que é possível graças às informações de controle encontradas no cabeçalho de cada um.

Nas redes comutadas a pacote são utilizadas dois tipos de técnicas para o transporte de pacotes: técnica por datagrama e por circuito virtual [Stallings 1997].

$\mathrm{Na}$ técnica por datagrama, cada pacote recebe tratamento individual, isto é, cada um deles poderá percorrer a rede por caminhos diferentes que são independentes uns dos outros. E quem decide o caminho percorrido por cada um são os elementos de rede localizados nos nós encontrados.

$\mathrm{Na}$ técnica de circuito virtual, o caminho percorrido por todos os pacotes é préestabelecido. Para isso, antes de iniciar a transmissão dos dados a estação de origem e a de destino trocam mensagens de controle que definirão a rota por onde todos os pacotes irão trafegar.

As vantagens da técnica por datagrama em relação à por circuito virtual é que ela está menos sujeita a problemas de conexão já que, caso haja algum problema em algum ponto da rede, os elementos de rede responsáveis pelo roteamento desviarão os pacotes para uma rota mais adequada, o que não acontece na outra técnica, que já tem uma rota pré-estabelecida. 
A vantagem da técnica baseada em circuito virtual é o fato de que uma rota é estabelecida entre as estações antes da transferência de informações, o que garante uma maior eficiência na fase de troca de informações porque não há a necessidade de tomar decisões de roteamento a cada nó, e há a garantia de que os pacotes serão entregues na ordem em que foram enviados, condições estas básicas para que os circuitos virtuais emulem adequadamente os circuitos reais. A desvantagem relaciona-se à necessidade da sinalização para o estabelecimento da conexão e ao desperdício de recursos caso o circuito virtual tenha baixa taxa de utilização [Stallings 1997].

\subsubsection{Protocolos TCP/IP e UDP}

Com o intuito de possibilitar a troca de informações entre componentes de uma rede IP de diferentes fabricantes, a ISO - International Organization Standardization definiu um modelo de referência que deveria ser seguido por todos os protocolos de comunicação interredes. Esse modelo recebeu o nome de Open System Interconnection - OSI.

O desenvolvimento de um único protocolo que especificasse todos os detalhes necessários para o perfeito funcionamento das diversas formas de comunicação seria complexo e trabalhoso. Os projetistas decidiram, então, projetar protocolos específicos para cada parte, e para garantir que as parte funcionem em perfeita harmonia, em vez de desenvolvidos separadamente, os protocolos são projetados e desenvolvidos em conjuntos completos e cooperativos [Comer 1998]. Algumas dessas "famílias" de protocolos estão descritas a seguir:

TCP/IP é um grupo de protocolos que funcionam conjuntamente, estabelecendo comunicação e transferência de dados entre computadores conectados em rede [Soares 2008]. Os dois protocolos se complementam, isto é, o IP fará a identificação dos endereços e irá assegurar que os dados sejam enviados através do meio físico e o TCP, por outro lado, verifica se os dados chegaram integralmente ao destino.

O TCP funciona como uma biblioteca de rotinas instaladas nos computadores de origem e de destino que aplicações como HTTP (Hyper Text Transmission Protocol), Mail, entre outras, utilizam para o transporte de dados. O protocolo utiliza uma técnica de segmentação de dados e os transmite em blocos menores chamados pacotes ou datagramas. Essa técnica possibilita ao TCP verificar se os pacotes chegaram corretamente ao destino ou se ocorreu 
alguma perda durante a transmissão, podendo fazer a retransmissão dos pacotes caso necessário. Ao contrario do TCP, o IP é um protocolo não-orientado a conexão, isto é, não há verificação de erro na transmissão, ele apenas desenvolve as funções de roteamento de pacotes pela rede. Este é responsável pelo transporte da mensagem entre redes e pela decisão de qual rota ela deve seguir através da estrutura do sistema para chegar ao seu destino [Soares 2008].

O desenvolvimento da arquitetura Internet TCP/IP foi patrocinado pela DARPA (Defense Advanced Research Projects Agency). A arquitetura, como descrito anteriormente, baseia-se principalmente em um serviço de transporte orientado à conexão fornecido pelo TCP e um serviço de rede não orientado à conexão (datagrama não confiável) fornecido pelo IP. Ela é organizada em quatro camadas conceituais construídas sobre uma quinta camada que não faz parte do modelo, a camada intra-rede [Comer 1998]. Os protocolos divididos em camadas são projetados de modo que a camada $\mathrm{n}$ de destino receba exatamente o mesmo objeto enviado pela camada $\mathrm{n}$ de origem.

Host A

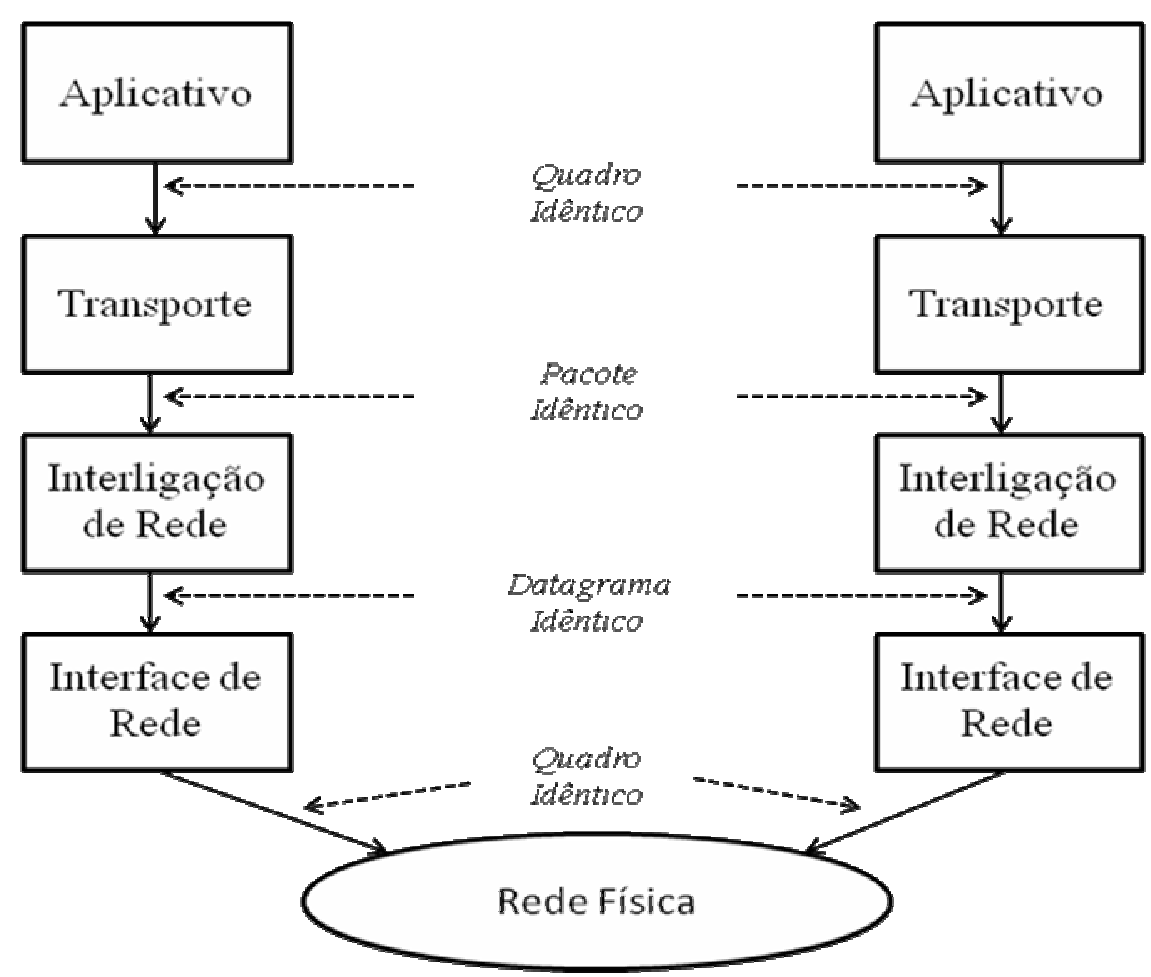

Figura 2.4 - Arquitetura do protocolo TCP/IP Fonte: [Modificado de Comer 1998] 


\subsubsection{Camada de Aplicativos}

Essa é a camada que permite que usuários possam rodar os programas aplicativos que acessam serviços disponíveis. Um aplicativo interage com um dos protocolos dos níveis de transporte para enviar ou receber dados. Cada um dos programas aplicativos escolhe o tipo de transporte necessário, que poderá ser uma sequiência de mensagens individuais ou um stream contínuo de bytes [Comer 1998].

\subsubsection{Camada de Transporte}

Após o tratamento na Camada de Aplicação, os dados passam para a Camada de Transporte, que possui como primeira função prover comunicação entre programas aplicativos, chamada de comunicação fim a fim. A camada utiliza protocolos que fornecem transporte confiável, assegurando que os dados cheguem íntegros e na seqüência correta. Para isso, o protocolo de transporte permite que a parte receptora envie confirmações e o transmissor retransmita pacotes perdidos [Comer 1998].

\subsubsection{Camada de Internet}

É a camada que trata dos dados passados de uma máquina para outra. A Camada de transporte manda para a camada de internet um pedido de envio da mensagem junto com uma identificação da máquina para a qual o pacote deverá ser enviado. O pacote, então, é encapsulado em um datagrama IP, suas informações de cabeçalho são preenchidas e usa o algoritmo de roteamento para decidir se entrega o datagrama diretamente ou o envia para um roteador e passa para a interface de rede apropriada para a transmissão [Comer 1998]. 


\subsubsection{Camada de Interface de Rede}

A camada de interface de rede é considerada o nível mais baixo do software TCP/IP. Ela recebe os datagramas IP da camada de Internet e os envia através de uma rede específica. Para realizar essa função nesse nível, os endereços IP - que são endereços lógicos - são traduzidos para os endereços físicos dos hosts ou gateways conectados a rede, definida como camada de hardware [Lemos, 1995].

O UDP (User Datagrama Protocol) tem como principal função multiplexar na origem e desmultiplexar no destino o acesso ao nível Inter-rede [Colcher 2005]. É bastante utilizado em aplicações em que a entrega rápida dos pacotes seja mais importante que a entrega confiável. Alguns exemplos para isso são aplicações de transmissão de voz ou de vídeo em que o atraso não é muito tolerável.

\subsection{VOZ SOBRE IP}

Acrônimo de Voice over IP, o VoIP, é uma tecnologia que permite a realização de chamadas sobre uma rede de dados IP como se estivesse usando a rede STFC. O surgimento dessa nova maneira de realizar ligações telefônicas vem redefinindo a arquitetura de um PABX, estagnada por muitos anos. Alguns componentes básicos da arquitetura de um sistema VoIP são citados a seguir [Soares 2008].

O controle de processo é um servidor cuja função é controlar todas as chamadas, desde seu estabelecimento até o processo de bilhetagem e controle de qualidade de chamada. Existem ainda os dispositivos de ponta, que são os telefones IPs ou softphones, que se conectam direta ou indiretamente a uma rede IP. Se conectados diretamente, necessitam de um endereço IP próprio. Caso sejam conectados indiretamente, o dispositivo que o interliga a rede passa a ter a função de controlar esse endereçamento. Outro componente com vital importância nos sistemas de comunicações são os chamados Gateways, com função de interligar diferentes tipos de mídia para a interconexão entre tecnologias diferentes para o mesmo serviço. No caso do VoIP, os Gateways têm a função de converter a sinalização e o canal de voz da rede IP para a STFC e vice-versa. 
Apesar de toda praticidade, economia e abertura de um leque de novas possibilidades e facilidades, um sistema VoIP encontra diversos obstáculos para o seu bom funcionamento. As redes IP, projetadas inicialmente para tráfego exclusivamente de dados, não davam o devido suporte para aplicações em tempo real. Até hoje existem diversas dificuldades encontradas por essa tecnologia. Abaixo, estão descritos os principais problemas e as conseqüências para a transmissão de voz sobre uma rede IP.

Perda de pacotes - a rede IP pode perder pacotes de voz se a qualidade de rede for ruim, se houver congestionamento na rede ou se o delay for muito variado. Alguns CODECs, do inglês Coder/Decoder, são capazes de corrigir pequenos defeitos ocasionados pela perda de pacotes, mas grandes perdas podem causar "picotamento" na voz. A maior causa de perda de pacotes é o congestionamento da rede que pode ser resolvida com o uso adequado de QoS Quality of Service [Soares 2008].

Delay - é o tempo que o pacote de voz leva para chegar da origem para o destino. O delay tem dois componentes:

- Delay Fixo: causado pelos processos de codificação e decodificação da voz analógica e pela propagação no meio. A ITU-T através do padrão G.114 define que em uma via de transmissão, o tempo de delay aceitável é de no máximo $150 \mathrm{~ms}$;

- Delay Variável: causado pelo congestionamento da rede e pela serialização dos pacotes nas interfaces de rede. A serialização é uma função dependente da velocidade do link e do tamanho do pacote. Por isso esse tipo é considerado variável, pois depende do tamanho do pacote que chega à interface para ser serializado.

Jitter - é a variação do delay da chegada dos pacotes no destino. Esse problema pode ser solucionado utilizando os buffers dos terminais de forma que iguale todos os delays dos pacotes. Mas se um pacote chegar muito atrasado em relação aos outros, os buffers não serão suficientes para corrigir o erro. 


\subsubsection{CODEC}

Para contornar os problemas relacionados a atrasos e requisitos mínimos de banda, os sistemas de comunicações VoIP utilizam os chamados CODECs para digitalizar a voz de acordo com alguns parâmetros e/ou requisitos do sistema. Os CODECs são programas ou dispositivos com algoritmos de compactação e descompactação específicos para um determinado formato de arquivo.

Um CODEC é um programa ou dispositivo com algoritmos de compactação e descompactação específicos para um determinado formato de arquivo. O CODEC converte o vídeo e o som analógico em sinais digitais e depois os comprime para diminuir o tamanho dos arquivos.

Cada CODEC provê certa qualidade de voz, gasta uma determinada largura de banda e apresenta um delay durante o processamento. O balanço de todas essas características levará ao administrador escolher o CODEC com a melhor relação custo/benefício. Uma medida comum usada para determinar a qualidade do som produzido pelos CODECs específicos é o MOS (Mean Opinion Score). Com o uso do MOS, uma ampla quantidade de ouvintes julgam a qualidade de uma amostra de voz numa escala de 1 a 5 . A partir desses resultados, é calculada a média dos valores para atribuir o MOS para aquela amostra [CISCO-CODEC, 2005]

Na Tabela 2.2 são apresentados alguns valores do MOS e do Delay para alguns CODECs específicos. 
Tabela 2-1 - Dados relativos a cada tipo de CODEC

\begin{tabular}{|c|c|c|c|}
\hline Método de Compressão & $\begin{array}{c}\text { Largura de Banda } \\
(\mathrm{kbit} / \mathrm{s})\end{array}$ & Valor MOS & Delay (ms) \\
\hline G.711 & 64 & 4.1 & 0.75 \\
\hline G.726 & 32 & 3.85 & 1 \\
\hline G.728 & 16 & 3.61 & 3 a 5 \\
\hline G.729 & 8 & 3.92 & 10 \\
\hline G.729 & 8 & 3.7 & 30 \\
\hline G.723.1 & 6.3 & 3.9 & 30 \\
\hline G.723.1 & 5.3 & 3.65 & 10 \\
\hline
\end{tabular}

\subsubsection{QoS}

Uma das principais funções da camada de transporte, citada na seção 2.2.1.2, é aumentar a qualidade de serviço (QoS) fornecida pela camada de rede [Lemos 1995]. A QoS pode ser definida por uma quantidade específica de parâmetros definidos na recomendação I350 (ITU I350, 1993) como a habilidade da rede ou dos componentes da rede para prover funções relacionadas à comunicação entre dois usuários.

Entre os parâmetros mais utilizados de qualidade de serviço, alguns já citados na introdução sobre VoIP, estão [Kamienski 2000]:

- Vazão, caracterizada como a taxa de bits transmitida por segundo [Lemos 1995];

- Latência, que pode ser entendida como o somatório dos atrasos impostos pela rede e equipamentos utilizados na comunicação;

- Jitter, pode ser entendido como a variação no tempo e na sequiência de entrega das informações;

- $\quad$ Taxa de Perdas,Taxa de Erros;

- $\quad$ Disponibilidade, que é uma medida da garantia de execução da aplicação ao longo do tempo. 
A QoS é muito importante em redes onde há a convergência entre voz e dados pois, assim como em qualquer outro tipo serviço oferecido, é indispensável um nível aceitável de qualidade para garantir o conforto e satisfação do usuário.

\subsubsection{Protocolos}

A premissa básica do VoIP é a do empacotamento de fluxos de áudio através de protocolos da Internet. Os desafios em relação a isso vieram em razão do modo como as pessoas se comunicam, isto é, a informação não só deve chegar do mesmo da mesma forma que foi transmitido, mas é necessário que ele faça isso em menos de 150 milissegundos [Meggelen 2007]. Se pacotes forem perdidos ou chegarem atrasados haverá uma degradação da qualidade da comunicação, o que significa que duas pessoas terão dificuldade de realizar uma conversa.

Os protocolos de transporte, que são coletivamente chamados de "a Internet", não foram originalmente concebidos para transportar fluxos de mídia no chamado "tempo real". Em um sistema de comunicação como esse, os terminais de comunicação foram desenvolvidos levando em conta transmissões em que alguns pacotes demorariam mais tempo pra chegar ou casos onde haveria a necessidade do envio de mensagens com pedidos de retransmissão, ou simplesmente aceitar a informação incompleta. Em uma típica conversa de voz, entretanto, esse mecanismo pode não funcionar com a qualidade desejada, conversas desse tipo não se adaptam muito bem a perdas de letras ou palavras, nem a atrasos entre os terminais de comunicação [Meggelen 2007].

A RTFC foi projetada especificamente para transmissão de voz e é perfeitamente adequada para esta tarefa do ponto de vista técnico. Já do ponto de vista da flexibilidade, suas falhas são evidentes. Já o VoIP mantém a promessa de integrar a transmissão de voz aos protocolos que fazem parte da rede de pacotes.

Os mecanismos para o transporte de uma ligação VoIP geralmente envolvem uma série de trocas de sinais entre os terminais (e os Gateways) que culminam em dois diferentes fluxos de mídia carregando as mensagens enviadas. Existem vários protocolos para lidar com isso [Meggelen 2007]. Nessa seção, serão descritos alguns daqueles que são mais importantes para o VoIP, e especificadamente para o Asterisk - software que será apresentado na seção 2.5. 


\subsubsection{H.323}

O H.323 é um protocolo que foi originalmente criado para fornecer um mecanismo de transporte IP para videoconferências. Tornou-se então o padrão básico para equipamentos de videoconferência, e logo ganhou fama de protocolo para o sistema VoIP. Entretanto, após muitos debates sobre qual dos protocolos (SIP, IAX ou H.323) iria dominar os sistemas VoIP, com o surgimento do Asterisk, ele foi fortemente rejeitado[Meggelen 2007].

\subsubsection{SIP}

Definido através da recomendação RFC 2543 [Handley Et Al 1999], o SIP é um protocolo do nível de aplicação que permite o estabelecimento, gerenciamento e encerramento de sessões multimídia, como, por exemplo, chamadas telefônicas através da rede IP.

O SIP se tornou um protocolo mais atraente para sistemas de telefonia IP, por ser um protocolo relativamente simples, principalmente quando se compara com o H.323, e possui uma sintaxe semelhante à de protocolos mais familiarizados no ambiente de comutação de pacotes, como HTTP e SMTP - Simple Mail Transfer Protocol.

É um protocolo que normalmente trabalha conjuntamente com outros protocolos, tais como [Colcher 2005]:

- $\quad$ MGCP (Media Gateway and Control Protocol), utilizado para controlar gateways de mídia sobre redes IP;

- $\quad$ MEGACO - Media Gateway Control Protocol, que se trata de um protocolo de sinalização utilizado entre Media Gateways e Media Gateways Controllers, sendo uma versão desenvolvida a partir do MGCP, mas que possui mais recursos;

- $\quad$ RTP e RTCP (Real Time Protocol e Real Time Control Protocol), que são usados para transportar dados e monitorar esse transporte;

- $\quad$ RTSP (Real-time Streaming Protocol), usado para a distribuição de conteúdo;

- SDP (Session Description Protocol), que especifica o formato para a descrição das informações em sessões multimídia.

O protocolo SIP possui dois tipos de agentes: os agentes usuários (UA - User Agent) e os servidores de rede [Gonçalves 2006]. Os agentes usuários podem ser divididos em agentes 
usuários clientes (UAC - User Agent Client) e agentes usuários servidores (UAS - User Agent Server).

Os chamados de clientes são aqueles que fazem uma chamada SIP para outro terminal. E os chamados servidores são aqueles que recebem a ligação de outro terminal. Os usuários SIP podem exercer ambas as funções. Alguns exemplos que podem ser citados de agentes usuários são: Telefones IP, Softphones e Gateways.

Os servidores de rede SIP, são divididos em quatro tipos distintos:

- Proxy Server: é responsável por intermediar as chamadas, recebendo as requisições do UAC e encaminhando para o UAS. Esse tipo de procedimento ajuda na segurança do sistema, pois, um cliente não saberá o endereço IP do outro. Além disso, ele exerce algumas funções de roteamento, controle de acesso a rede e autenticação.

- Redirect Server: é um servidor que fornece informações ao cliente sobre o endereço IP do servidor.

- Register Server: responsável por registrar todos os clientes SIP que solicitam autenticação.

- Servidor de Banco de Dados: é o local onde são armazenadas as informações de identificação do cliente, como login, senha, ramal, endereço IP.

\subsubsection{IAX}

É um protocolo desenvolvido pela Digium, criadora e desenvolvedora do Asterisk, com a finalidade de possibilitar a comunicação entre servidores do Asterisk, daí o nome IAX Inter-Asterisk Exchange Protocol. Oficialmente, a versão atual é IAX2, pois o apoio ao desenvolvimento do IAX foi retirado, o que fez com que os dois termos sejam usados para a mesma versão [Meggelen 2007].

É importante enfatizar que apesar do que foi dito anteriormente, o IAX não é um protocolo limitado somente ao Asterisk, mas, seu padrão é livre a utilização de qualquer pessoa e é suportado por vários outros projetos de telecomunicações. Este é um protocolo de transporte parecido com o SIP que usa uma única porta UDP tanto para o canal de sinalização quanto para fluxos de mídia. 
O IAX também tem capacidade de truncar múltiplas sessões em um único tronco de fluxo de dados, o que pode ser uma vantagem em relação à largura de banda quando são enviadas mensagens por diferentes canais simultaneamente para um mesmo receptor remoto. O truncamento permite que múltiplos fluxos de mídia possam ser representados por um único cabeçalho de datagrama, o que diminui o overhead associado a cada um dos canais, além de diminuir a latência e reduzir a potência e a largura de banda requerida.

\subsection{SEGURANÇA DA INFORMAÇÃO}

Uma grande preocupação que existe na maioria dos sistemas corporativos onde há um tráfego de informações confidenciais é manter certo grau de segurança para que essas informações não sejam extraviadas. Algumas das possibilidades existentes para se proporcionar isso foram descritas nos tópicos a seguir.

\subsubsection{Firewall}

É definido como a barreira inteligente entre duas redes, geralmente uma rede local e a Internet, através da qual o tráfego de informações é autorizado [Hazari 2000].

Esse dispositivo que, normalmente, é uma combinação de software e hardware, exerce a função de negar acessos através da implementação de filtros nas camadas 3 e 4 do modelo OSI [Colcher 2005].

Alguns tipos de firewall são:

- De filtro - à medida que os pacotes são transmitidos da camada de enlace (camada 2 do modelo OSI) para a camada de rede (camada 3 do modelo OSI), eles serão analisados e, de acordo com algumas regras adotadas, podem, por exemplo, ser descartados, negados, ou ter seu acesso permitido.

- De proxy - é um software que atua como intermediário entre um cliente e um servidor. Ele fica responsável por receber requisições dos clientes, refazê-las e repassar as respostas de volta aos clientes. 
Para uma proteção mais eficiente contra ameaças a um sistema, podem ser usados outros mecanismos descritos nos próximos tópicos.

\subsubsection{Criptografia}

Criptografia é o nome dado a técnica de utilizada para transformar dados em um código secreto [Cobb 2004]. Para se decifrar a uma mensagem criptografada é necessário que se tenha uma senha ou chave secreta específica.

Os dois principais tipos de criptografia utilizam chaves simétricas e assimétricas. No caso dos algoritmos que utilizam a simétrica, os dados são cifrados e decifrados com a mesma chave secreta. Uma grande vantagem desse tipo de técnica é a grande velocidade de criptografia e seu maior problema é que as chaves estão mais expostas a mais pessoas, tornando sua administração mais difícil. Alguns exemplos de algoritmo que utilizam esse sistema são: DES (Data Encryption Standart) ou DEA (Data Encryption Algorithm), AES (Advanced Encryption Standart), IDEA (International Data Encryption Algorithm) e RC5 (Rivest Cipher 5) [Cobb 2004].

Já a criptografia assimétrica, também chamada de Diffe-Hellman encryption - por conta do nome de seus criadores Whitfield Diffie e Martin Hellman [Cobb 2004], utiliza duas chaves: a pública e a privada. Uma mensagem cifrada pela chave pública só pode ser decifrada pela sua respectiva chave privada e vice-versa. Além disso, uma chave não pode ser decifrada a partir da outra. A vantagem desse sistema em relação ao simétrico é sua maior facilidade na administração das chaves, já que caso a uma das chaves seja interceptada, o conteúdo da informação cifrada por ela não poderá ser decifrado. Por outro lado, a velocidade do processo de criptografia é menor. Alguns exemplos de algoritmo para essa técnica são: DAS (Digital Signature Algorithm) e PGP (Pretty Good Privacy) [Cobb 2004].

\subsubsection{VPN}

A VPN (Virtual Private Network) é uma rede privada de tráfego de dados que é construída através da utilização de uma rede pública, como, por exemplo, a Internet. Nesse 
sistema uma rede pública é utilizada para a conexão de diferentes nós, ou redes, ao invés de links dedicados entre os mesmos [Cobb 2004].

A utilização da internet na conexão entre terminais de redes privadas é uma boa alternativa em relação à redução de custos, se comparado com links dedicados, porém fica mais frágil em relação aos fatores de segurança da informação.

Uma forma de aumentar a segurança das informações no trajeto pela rede pública é utilizar a criptografia. Um exemplo disso são as SVPNs (Secure VPN), elas funcionam como um túnel mais seguro criado entre os dois nós que utilizam a rede pública para se comunicar. Caso os dados sejam capturados, eles não poderão ser decifrados.

Alguns protocolos que podem ser usados nas VPNs são: IPSec (IP Security), SSL (Secure Socket Layer), TLS (Transport Layer Security) e PPTP (Point-to-point tunneling protocol) [Cobb 2004].

\subsection{ASTERISK}

Em 1999 foi criado pela Digium Inc. um software revolucionário no mercado de telecomunicações, o Asterisk. O software recebeu esse nome em analogia ao símbolo, *, que nos sistemas operacionais Unix e Linux representa um wildcard que equivale a qualquer caractere, qualquer arquivo. A analogia foi feita por ser, o Asterisk, destinado a integrar peças de telefonia, seja hardware ou software, a aplicações [Golçalves 2006].

O Asterisk possibilita a implementação de todas as funções de um PABX convencional e outras mais [Oliveira 2008]. É totalmente baseado em software livre e possibilita muitos benefícios devido ao seu suporte a diversos protocolos VoIP.

Além de substituir um PABX convencional, ele torna possível, a um baixíssimo custo, agregar funções disponíveis apenas em equipamentos PABX de grande porte, os quais custam algumas centenas de milhares de reais [Oliveira 2008].

Em uma comunicação VoIP existem vários agentes participantes de cada sessão. Esses agentes são, por exemplo, PCs (Personal Computer) - equipados com Sofphones, ou Telefones IP, que irão participar desse tipo de comunicação implementando uma pilha TCP/IP para poderem se comunicar via Internet. 
Tratando de maneira simplificada, para que exista comunicação entre dois pontos de uma rede VoIP é usada uma combinação de dois elementos: um CODEC para codificação de áudio e um protocolo de sinalização capaz de lidar com questões relacionadas à sinalização de telefonia [Oliveira 2008]. O protocolo de mais difundido nesse setor atualmente é o SIP, graças às várias características já apresentadas na seção 2.3.3.2.

Algumas dessas funcionalidades acrescentadas pelo PABX IP que podem ser usadas principalmente em ambientes corporativos são [Gonçalves 2006]:

- Conectar funcionários trabalhando de casa com o PABX do escritório sobre conexões de banda larga;

- $\quad$ Conectar escritórios em vários estados sobre IP. Que pode ser feito através da Internet ou de uma rede IP privada;

- Construir aplicações de resposta automática por voz, que possibilitam a conexão do usuário ao sistema de pedidos, por exemplo, ou ainda outras aplicações internas;

- Dar acesso ao PABX da empresa para usuários que viajam, conectando sobre VPN de um aeroporto ou hotel, entre outras possibilidades. 


\subsubsection{Arquitetura do Asterisk}

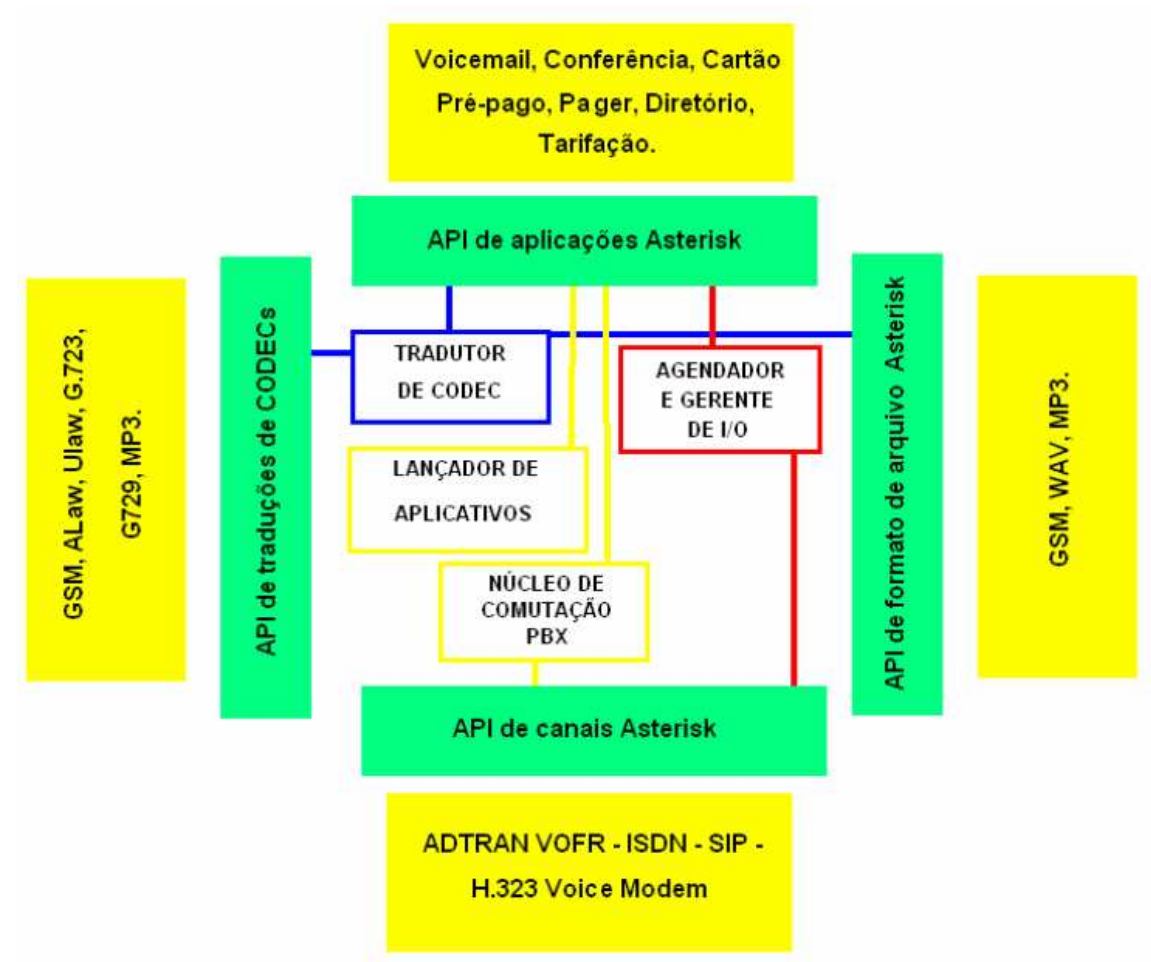

Figura 2.5- Arquitetura Asterisk - Fonte: [Gonçalves 2006]

Os conceitos relacionados com os elementos da Figura 2.5, da arquitetura do Asterisk, serão apresentados a seguir.

\subsubsection{Canais}

Um canal pode ser resumido como uma linha telefônica na forma de um circuito de voz digital. Ele geralmente pode ser visto como uma combinação de CODEC e protocolo de sinalização. Em sistemas digitais, que normalmente utilizam a técnica PCM (Pulse Code Modulation), os sinais analógicos são codificados em taxas de 64Kbps sem compactação [Gonçalves 2006].

No VoIP podem existir dois tipos diferentes de canais: os FXO (Foreing Exchange Station) e os FXS (Foreing Exchange Office). Eles representam interfaces responsáveis por permitir a comunicação entre os equipamentos VoIP e os de telefonia analógica. O FXS 
fornece sinal para um telefone e pode ser ligado no tronco do PABX. Já o FXO recebe sinalização da operadora STFC, ou de um ramal da central PABX.

A Figura 2.6 apresenta ligações básicas com canais FXO e FXS.

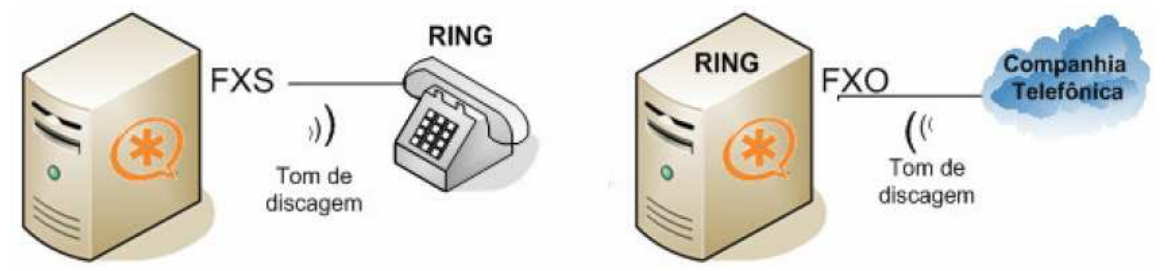

Figura 2.6- Ligação entre Canais FXO e FXS. Fonte: [Gonçalves 2006]

O Asterisk, do ponto de vista de canais, não diferencia o que é telefone ou linha telefônica, tudo é visto como um canal. Para o processamento desses canais de voz, o Asterisk utiliza a CPU (Central Processing Unit) do servidor, ao invés de usar um DSP (Digital Signal Processing) específico para cada canal. E, apesar de com isso ter reduzido os custo com as placas E1/T1, tornou o sistema muito dependente da CPU. Daí a necessidade de fazer um bom dimensionamento do sistema antes da implantação e, de preferência rodá-lo em máquinas dedicadas [Gonçalves 2006].

\subsubsection{Protocolos Asterisk}

Para que haja comunicação entre diferentes terminais é preciso de um protocolo de sinalização que estabeleça conexões, determine qual o ponto de destino, faça identificação de chamada, entre outras coisas. Hoje o protocolo mais usado entre os usuários de sistemas de redes IP é o SIP, embora o IAX tenha se mostrado cada vez mais forte, principalmente, quando se trata de trunking e NAT (Network Address Translation) [Gonçalves 2006]. Entre os protocolos que o Asterisk suporta estão:

- SIP

- $\mathrm{H} .323$

- IAX

- $\mathrm{MGCP}$ 


\subsubsection{CODECs Asterisk}

Em sistemas VoIP, um codificador pode ser descrito, de maneira mais simplificada, como um componente responsável por analisar os dados que chegam e determinar o que existe de redundante nessa informação digital que pode ser retirada durante o processo de conversação de maneira que não comprometa a qualidade da informação. O decodificador é responsável pelo processo inverso. Esse procedimento é realizado para reduzir o máximo possível a quantidade de banda necessária [R. Neto 2006].

Os CODECs suportados pelo Asterisk são [Gonçalves 2006]:

- $\quad$ G.711 ulaw - usado nos EUA - (64 Kbps)

- $\quad$ G.711 alaw - usado na Europa e no Brasil - (64 Kbps)

- $\quad \mathrm{G} 723.1-(5.3-6 \mathrm{Kbps})$

- $\quad$ G.726 - (32Kbps no Asterisk)

- $\quad \mathrm{G} .729-(8 \mathrm{Kbps})$

- $\quad \mathrm{GSM}-(12-13 \mathrm{Kbps})$

- $\quad$ iLBC $-(15 \mathrm{Kbps})$

- $\quad$ LPC10 - (2.5 Kbps $)$

- $\quad$ Speex - $(2.15-44.2 \mathrm{Kbps})$

\subsubsection{Aplicações do Asterisk}

Para estabelecer uma conexão entre as chamadas de entrada e as de saída são utilizados, muitas vezes, alguns recursos adicionais. Alguns recursos do Asterisk que podem ser citados são [Gonçalves 2006]:

- $\quad$ Correio de Voz - é um tipo de serviço parecido com uma secretária eletrônica ou caixa de mensagens de celular, isto é, se na tentativa de realizar uma chamada o atendente estiver ausente ou como telefone ocupado, será recebido um comando que permite deixar uma mensagem em sua caixa postal;

- Sala de Conferência - permite que vários usuários participem conjuntamente de uma mesma chamada; 
- $\quad$ Sistema de Mensagens Unificadas - é um sistema que possibilita que mensagens de e-mail, de correio de voz, ou de fax sejam encaminhadas para uma mesma caixa postal do usuário;

- $\quad$ Recebimento e envio de fax;

- Distribuidor Automático de Chamadas (DAC) e Fila de Atendimento - a pessoa que originou a chamada se autentica em uma fila de atendimento, o distribuidor, então, verifica se algum dos atendentes está livre. Se estiver livre, ele passa a chamada para o atendente, caso contrário, ele mantém a pessoa na fila, normalmente, fazendo com que ela escute algum tipo de música ou propaganda da empresa;

- Música de Espera - recurso usado principalmente para manter as pessoas esperando na fila de atendimento;

- $\quad$ Unidade de Resposta Automática (URA) - permite que uma pessoa seja atendida por um sistema automático que poderá dar algumas soluções de serviços sem necessidade de que a chamada seja recebida pelos atendentes, tornando o sistema mais dinâmico.

\subsubsection{Hardware de Telefonia para o Asterisk}

No mercado de telefonia já existem alguns fabricantes que produzem placas de telefonia e outros equipamentos para serem usados junto ao Asterisk. Entres as placas que provavelmente serão mais usadas no Brasil podemos citar:

- $\quad$ X100P - é uma placa simples, que possui uma porta FXO que pode ser conectada à rede pública ou a uma interface de ramal PABX.

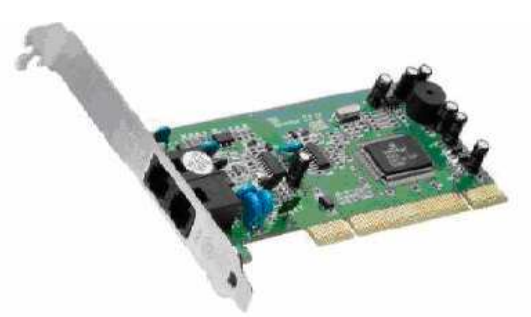

Figura 2.7 - Placa X100P. Fonte: [Gonçalves 2006] 
- $\quad$ TDM400P - com 4 portas E1/T1.

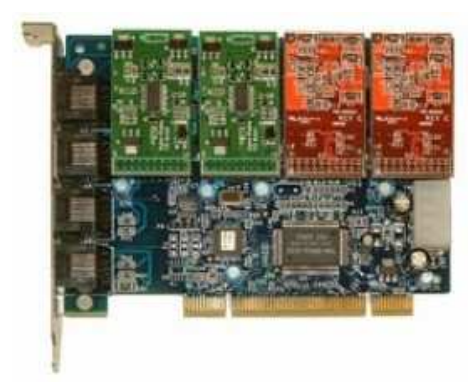

Figura 2.8 - Placa TDM400P. Fonte: [Gonçalves 2006]

- $\quad$ TE405P - com 4 portas E1/T1.

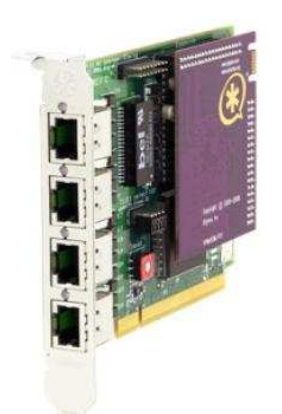

Figura 2.9 - Placa TE405P. Fonte: [Gonçalves 2006]

\subsubsection{Hardware Mínimo Requerido}

Na seção 2.5.1.1 foi citado que para o processamento dos canais de voz, o Asterisk utiliza uma CPU. Essa característica limita o desempenho do PABX de acordo com o potencial de processamento da CPU.

Para aplicação do Asterisk no desenvolvimento de servidores de VoIP mais robusto e que suportem uma quantidade de canais maior, é interessante que o Asterisk tenha prioridade alta em relação ao acesso ao barramento do processador e que as outras tarefas não diretamente relacionadas com o Asterisk tenham prioridade baixa [Maggelen 2007].

Na Tabela 2.2 foi apresentada uma descrição simplificada do hardware mínimo necessário para implementar um PABX usando Asterisk. 
Tabela 2-2 - Hardware mínimo requerido. Fonte [Modificado de Meggelen 2007]

\begin{tabular}{lll}
\hline Propósito & Número de Canais & Hardware Mínimo Recomendando \\
Sistema hobby & Não mais que 5 & $400 \mathrm{MHz}$ x86, 256 MB RAM \\
\hline Pequenos escritórios & 5 a 10 & $1 \mathrm{GHz} \times 86,512 \mathrm{MB}$ RAM \\
\hline $\begin{array}{l}\text { Sistema para empresas } \\
\text { de pequeno porte }\end{array}$ & Até 25 & $3 \mathrm{GHz}$ x86, 1 GB RAM \\
\hline $\begin{array}{l}\text { Sistemas de médio a } \\
\text { grande porte }\end{array}$ & Acima de 25 & $\begin{array}{l}\text { CPU dupla, possibilidade também de } \\
\text { múltiplos servidores numa arquitetura } \\
\text { distribuída }\end{array}$ \\
\hline
\end{tabular}

\subsubsection{Sistema Operacional}

O Asterisk foi criado para funcionar em plataformas Linux, apesar de rodar em sistemas como, por exemplo, o BSD e o OS X. Na plataforma Linux algumas distribuições como RedHat, Mandrake, Fedora, Debian Sarge 3.1, foram utilizados com o Asterisk com bastante sucesso [Gonçalves 2006]. 


\section{CENÁRIO}

Os sistemas VoIP vêm se tornando cada vez mais presentes em pequenas, médias e grandes empresas. Além disso, a adoção dessa tecnologia por instituições públicas também tem se tornado cada vez mais freqüente. A Câmara dos Deputados, observando as principais tendências de mercado, resolveu investir em tecnologia para adequar sua rede de telefonia para o novo paradigma baseado em uma rede IP.

Detentora de uma das maiores centrais telefônicas privadas do país, a Câmara possui uma central telefônica MD110 proprietária, versão BC12. A diferença fundamental entre o sistema MD110 e outros sistemas PABX reside principalmente nas vantagens oferecidas pela sua arquitetura descentralizada, que proporciona maior segurança nas comunicações, e na possibilidade de evolução para versões futuras, garantindo a preservação do investimento inicial ao longo de muitos anos. Por conta disso, apesar da existência relativamente longa do sistema de telefonia (quase 20 anos), a central instalada conseguiu se manter atualizada ao longo dos últimos anos, incorporando a ela novos módulos que possibilitaram o acompanhamento do avanço tecnológico ao longo dos anos.

Porém, essa possibilidade de incorporação de novas tecnologias se estagnou nos últimos anos. No inicio dos anos 2000, a proprietária da tecnologia lançou seu novo PABX, baseado em um sistema IP, o MX-ONE. Com o lançamento do sucessor do MD110, o fabricante parou de oferecer tecnologias modulares para a incorporação das novas tecnologias que vinham surgindo e, com isso, a Câmara se viu obrigada a fazer algo para manter o seu sistema em constante evolução e decidiu implantar um sistema de voz baseado na rede IP. Porém, diversos fatores devem ser considerados para uma análise mais cuidadosa desse novo sistema.

O MD110, ainda que um sistema de telefonia que está ficando ultrapassado, possui suporte para ramais IP, interligando-se, assim, como a rede de dados coorporativa ou mesmo com a Internet. A idéia, segundo as principais tendências atuais, é utilizar o protocolo SIP para prover esse tipo de ligação, devido às suas vantagens frente aos demais protocolos listado anteriormente. O problema na hora do projeto surgiu da falta de compatibilidade entre o MD110 e o protocolo SIP. O PABX da Câmara só dava suporte ao protocolo H.323, o que resultou na necessidade de um estudo mais profundo e detalhado sobre as possíveis maneiras 
de migrar um sistema legado para um sistema baseado na rede IP, convergindo assim o sistema de telefonia para um sistema mais moderno.

A Câmara possui atualmente cerca de 6000 (seis mil) ramais instalados. Deste total, cerca de 3500 (três mil e quinhentos) são ramais analógicos e os demais são ramais digitais, uma vez que o PABX só trabalha com esses dois tipos de ramais atualmente. Além das placas adquiridas, é necessária também a compra de licenças junto ao proprietário para que essas placas possam ser usadas para ofertar ramais. Atualmente, as licenças para ramais analógicos encontram-se praticamente esgotadas, enquanto as licenças para ramais digitais ainda possuem uma folga de cerca de 850 ramais a serem instalados.

A estrutura da rede de telefonia da Câmara pode ser entendida de acordo com o esquema mostrado na Figura $3.1 \mathrm{O}$ primeiro bloco, mostra o PABX em si. Como o sistema é descentralizado, cada LIM funciona como se fosse uma central independente. Além disso, cada um dos três módulos de um LIM são interconectados entre si e possuem conexões também com os demais LIMs. Porém, a principal ligação dos LIMs é a que é feita com os ramais em si, atingindo o usuário final

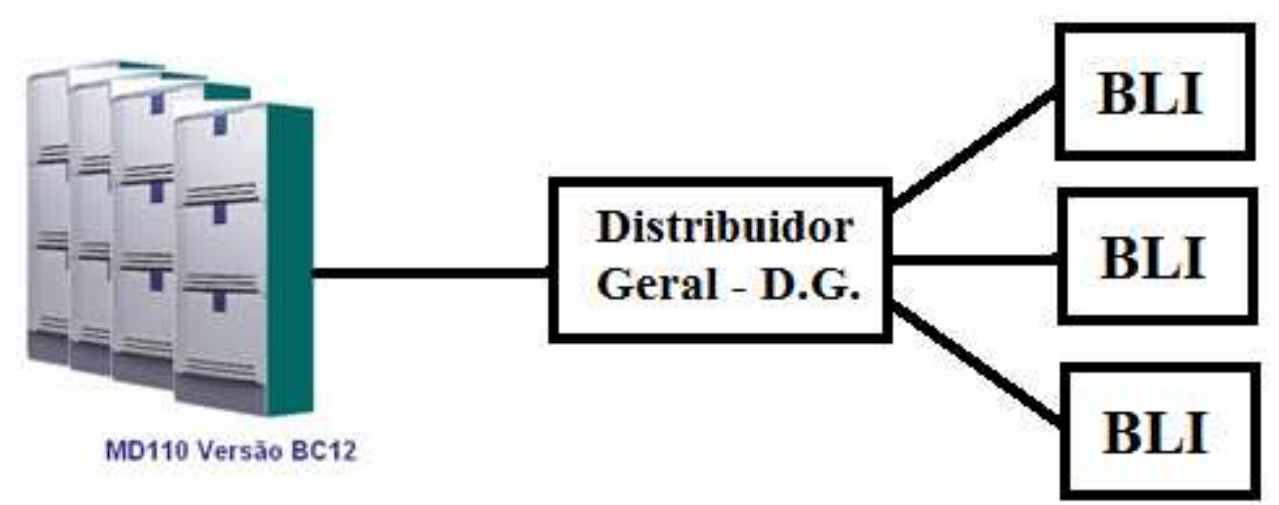

Figura 3.1 - Modelo do Hardware Proprietário, MD110.

Cada placa de um módulo de um LIM, possui saída para 8 ramais. Em todas essas saídas, um fio é usado para conectar a placa ao aparelho do ramal propriamente dito. O fio que sai da placa, passa inicialmente pelo Distribuidor Geral, D.G. - uma espécie de sala que concentra todos os fios oriundos da central telefônica e os encaminha através de ligações com fusíveis ou pontes diretas para os diversos prédios que compõem a Câmara. 
Após passar pelo D.G., o sinal de linha é encaminhado para um BLI (Bloco de Ligação Interna) que tem a função de distribuição final dos sinais telefônicos advindos da central. Cada BLI pode suportar até 50 pares de fios e os distribui para um perímetro mais reduzido. É comum cada corredor da Casa possuir um BLI que distribui o sinal do ramal de acordo com as demandas do local.

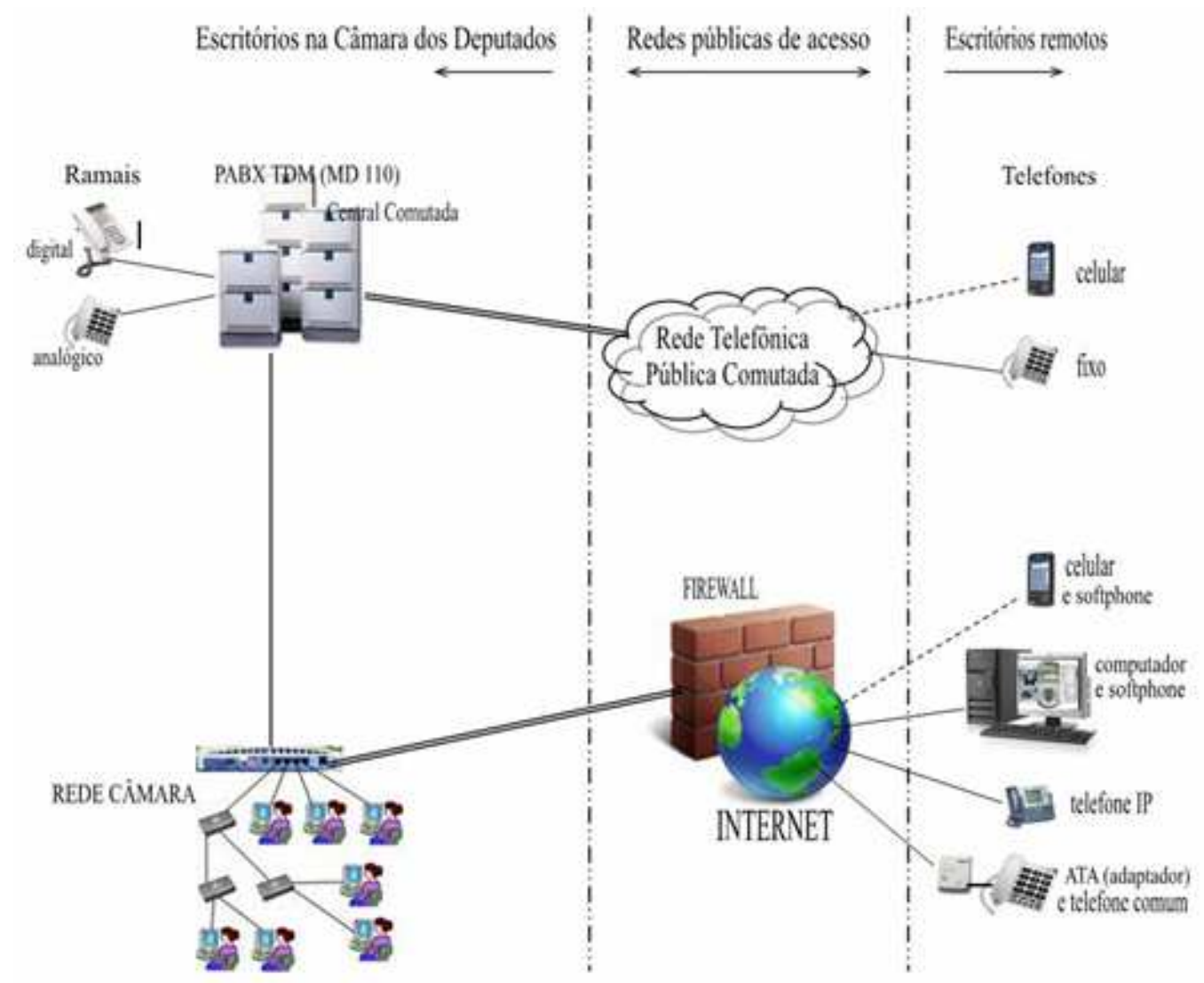

Figura 3.2 - Rede Telefônica da Câmara dos Deputados

A rede telefônica da Câmara dos Deputados, como apresentada na Figura 3.2, ainda não é uma rede completamente estruturada, de forma que existem dificuldades na manutenção de ramais devido a certa complicação de se identificar as conexões de um ramal quando este apresenta defeito. Porém, a alta qualificação e conhecimento prático da estrutura da rede telefônica que os técnicos de telefonia que trabalham no processo de manutenção possuem, acaba possibilitando um bom manuseio na hora de se encontrar e resolver problemas em ramais. Algumas partes da Casa possuem também uma rede estruturada, de modo que a rede 
telefônica e a rede de dados ocupam o mesmo espaço de uma forma muito mais inteligível a qualquer técnico, mesmo que este não possua experiência de manutenção prática do local.

A Câmara conta ainda com uma rede interna de dados para acesso à Internet e à Intranet. A chamada Rede Câmara abrange todo o complexo de prédios que compõem a Casa. Em uma rede mais bem estruturada e mais descentralizada, o serviço de acesso à Internet é possível em qualquer parte da Câmara com o uso de um computador, um login e senha, fornecidos pelo CENIN - Centro de informática. O CENIN é o responsável por gerenciar toda a parte de dados da Casa. Apesar de já haver pressões internas, a parte de voz e dados ainda é bem dividida, existindo o Departamento Técnico, responsável pela parte de telefonia, e o Centro de Informática, responsável pela parte de dados. As principais tendências tecnológicas apontam para uma breve convergência desses dois tipos de serviço, de modo que a rede de telefonia seja integrada à rede de dados para prover os diversos serviços possíveis, como chat, VoIP, HTTP, dentro outros [Soares 2008].

Segundo informações do CENIN, a rede de dados da Câmara já está toda preparada para receber tráfego de voz. Como todas as seções da Casa contam com acesso à Internet a partir da Rede Câmara, a implantação de um sistema de voz sobre IP já teria um alcance total dentro da instituição, bastando ser feitas algumas adaptações, principalmente de QoS, nas configurações de roteadores, switches, firewall, etc.

O tráfego de voz da Câmara é composto basicamente por dois tipos básicos: o político e o administrativo. O tráfego considerado de cunho político encontra-se principalmente nos gabinetes dos deputados e nas lideranças de partidos. Cada deputado possui atualmente em seu gabinete um total de 5 ramais, sendo dois digitais, dois analógicos e um de fax, que também pode ser usado como analógico.

Existem ainda os ramais de característica administrativa. Apesar de aparentar ser essencialmente o mesmo tipo de tráfego, é notória a diferença entre os dois tipos. Por exemplo, nas segundas e sextas feiras, a presença de deputados na Casa é de número bem reduzido, de forma que isso acaba influenciando diretamente no tráfego de ligações de cunho político. Já os ramais considerados de caráter administrativo, são usados intensamente de segunda à sexta, não acompanhando o crescimento do tráfego dos gabinetes de terça à quinta. Mas apesar de tráfegos com características diferentes, um consenso surge na necessidade de novos ramais e fica cada vez mais evidente a importância de uma ampliação da central existente. Porém, se essa ampliação for feita utilizando apenas os recursos e tecnologias já 
implantadas na instituição, existe o risco do sistema de telefonia ficar estagnado no tempo. Por isso surge a necessidade de convergir a rede atual baseada no STFC para uma rede IP.

O principal problema surgiu quando se pensou na ampliação da central MD110 existente. Se fosse utilizado um hardware de fabricante diferente, muitas facilidades poderiam ser perdidas no processo de interconexão entre a central existente e a central ampliada. $\mathrm{O}$ protocolo Q-SIG deveria possibilitar a interconexão sem falhas entre centrais de fabricantes diferentes, mas não é o que se vê na prática. Além disso, os aparelhos digitais são também do mesmo fabricante, de forma que uma ampliação de central utilizando equipamentos de outros fabricantes geraria problemas de incompatibilidade com esses ramais digitais.

Por conta desses fatores, a possível solução para o problema de ampliação e convergência da central possui dois ramos bem definidos. Um deles seria utilizando a nova geração de equipamentos do mesmo proprietário do hardware, o MX-ONE, considerado uma evolução do MD110, que atenderia a todos os requisitos de projeto. A outra solução possível seria a adoção de um software livre para fazer o papel de PABX IP. Ambas as possíveis soluções foram estudadas conforme mostrado nos próximos capítulos. Em seguida é apresentada a solução escolhida como sendo a melhor para o cenário existente. 


\section{SOLUÇÕES}

Nesse capítulo serão descritas as duas soluções propostas para a ampliação da Central PABX da Câmara: uma solução em hardware e outra em software. Em um primeiro momento serão descritas as características de cada uma das soluções e, então, apresentada uma proposta de como cada uma delas poderia ser implementada, visando estabelecer qual seria a mais vantajosa.

Para que fosse realizada uma ligação eficiente entre o sistema existente na Câmara e o sistema que se deseja implementar foi feito um estudo de engenharia de tráfego para verificar a demanda por canais para prover um GoS (Grade of Service) mínimo. Grau de serviço é a medida utilizada para definir um desempenho desejável em um sistema troncalizado, pela especificação da chance de um usuário obter, em uma tentativa, acesso ao canal, dado um número especifico de canais disponíveis no sistema [GARG, 2007]. Para esse fim, um estudo estatístico foi realizado em ramais considerados de cunho político, visto que os futuros ramais IP inicialmente serão instalados para os gabinetes dos deputados.

O estudo foi feito a partir de uma amostra de 200 ramais de diversos gabinetes. Considerando horário e dia de pico (quarta-feira das 15 às 17 horas), foi possível estabelecer uma média de 0,12 Erlang por ramal nos gabinetes. Considerando, posteriormente, que a central ampliada daria suporte inicialmente para 600 ramais (513 gabinetes mais uma margem de guarda), teríamos uma expectativa final de carga de 72 Erlangs. Considerando, ainda, que o sistema é do tipo BCC (Blocked Calls Cleared), no qual, caso uma chamada não encontre um canal, ela é descartada pelo sistema, deve-se consultar a tabela de Erlang B para fazer uma análise dos parâmetros necessários [GARG, 2007].

Usualmente uma taxa aceitável de erro considerada pelas empresas de telecomunicações é de $2 \%$ e esse foi o parâmetro usado como GoS para esse caso. Fazendo a consulta na Tabela Erlang B, foi possível verificar que, para essa probabilidade de perda, seriam necessários 84 canais. Como essa interconexão entre as centrais será feita através de troncos E1, seria interessante, então, que ter um mínimo de 3 portas E1, o que proporcionaria uma GoS de menos de $1 \%$. Caso se julgue necessário, essa conexão poderia ser feita a partir de 4 portas E1 apenas para casos de falhas ou de crescente demanda posterior por ramais IP, de forma que não é considerado fundamental para o sistema funcionar eficientemente. Caso fossem 
utilizadas 4 portas E1, ter-se-ia a possibilidade de ampliação, sem prejuízo dos requisitos básicos de funcionamento, para mais de 290 ramais, fazendo assim o sistema suportar até 890 novos ramais IP.

A seguir, serão descritas algumas características das duas soluções e qual delas foi escolhida como a solução mais adequada para o cenário da Câmara.

\subsection{SOLUÇÃO EM HARDWARE}

Para esse modelo de solução foi escolhido o MX-ONE que é um hardware proprietário. Apesar da existência de várias outras soluções muito eficientes no mercado, essa foi escolhida em particular por se tratar de um equipamento do mesmo fabricante do PABX instalado hoje na Câmara dos Deputados. Primeiramente, foi feito um estudo do hardware que pode ser resumido como: uma evolução do MD-110.

\subsubsection{MX-ONE}

O hardware MX-ONE baseia-se em uma arquitetura de processamento verdadeiramente distribuída. O sistema é constituído por nós: LIMs (Módulos de Interface de Linha). Todos os LIMs podem funcionar como um nó independente ou em combinação com outros LIMs para formar um sistema único. Uma vez que se trata de um sistema único, o gerenciamento é sempre totalmente centralizado. O conceito é flexível em termos de centralização contra descentralização; ambos os enfoques podem ser adaptados dependendo da situação específica do cliente. O MX-ONE também dá suporte a uma grande variedade de interfaces novas e tradicionais, tais como IP, ISDN e interfaces convencionais digitais e analógicas. Como conseqüência, ele interage facilmente com sistemas de telecomunicação convencionais ou integralmente baseados em IP.

Uma característica importante para os objetivos traçados é que o MX-ONE atende integralmente a operações em IP. A nova versão suporta o protocolo SIP tanto para o lado do usuário quanto para o lado do tronco. Uma vez que a ampliação pretendida é baseada em VoIP e preferivelmente usando o protocolo SIP [Meggelen 2007] essa se torna uma 
característica importante para esse equipamento. Outra característica importante é a interoperabilidade entre o MX-ONE e o MD-110. Possibilita uma migração fácil, de modo que um ramal no MX-ONE será sempre visível com todas as facilidades já existentes anteriormente por um ramal em um LIM MD-110.

O MX-ONE é constituído de dois módulos básicos: o servidor e o Media Gateway. Ambos os módulos podem ser combinados para formar um sistema completo ou um LIM. Para a escolha do servidor, é sugerida a opção Embedded Server Unit (ESU). Utilizar-se-ia um servidor blade (em lâminas), que é usado para atualizar as instalações MD110 já existentes e justamente por isso foi feita a escolha desse tipo de servidor. A função de um Media Gateway é servir de interface entre os mundos de telecomunicações por IP e convencional [Ericsson 2006]. Para o trabalho proposto seria interessante usar a solução MXONE Compact SM, utilizando um rack de 19 polegadas (ocupa 2U). É composto de um ESU e um Media Gateway. Essa combinação é a mais apropriada para fazer uma migração de um sistema MD110 para o sistema MX-ONE [Ericsson 2006]. Trata-se de um PABX-IP de 700 linhas para ramais IP. O Media Gateway usado seria o Media Gateway Classic, perfeito para ambientes em que interfaces IP e convencionais estão presentes. Suporta todas as interfaces convencionais para o MD110 [Ericsson 2006].

Algumas características que podem ser destacadas no MX-ONE são [Ericsson 2006]:

- $\quad$ É uma solução híbrida confiável e com recursos de IP;

- Recursos de mobilidade avançada e centrados no usuário incluídos no software básico do sistema;

- $\quad$ Suporte para terminais de sistema fixos e sem fio;

- $\quad$ Escala de até 10.000 sistemas em rede;

- $\quad$ Suporte a terminais móveis públicos e terminais fixos;

- $\quad$ Suporte a exibição de nomes e números de chamada também em telefones analógicos;

- Solução integrada que identifica locais para chamada de emergência e terminais IP;

- $\quad$ Upgrade simples disponível para cliente MD-110, entre outras. 
Tabela 4.1 Dados Técnicos do MX-ONE. Fonte [Ericsson 2006]

\begin{tabular}{lll}
\hline Capacidade & & \\
\hline $\begin{array}{l}\text { CAPACIDADE DO MX-ONETM } \\
\text { Telephony System -Telephony Switch }\end{array}$ & $\begin{array}{l}\text { Máximo por LIM } \\
\text { (Line Interface Module, } \\
\text { Módulo de Interface de Linha) }\end{array}$ & Máximo por sistema \\
\hline Número de usuários & 640 & 50.000 \\
\hline Número de LIMs & - & 124 \\
\hline Ramais IP & 640 & 50.000 \\
\hline Ramais móveis & 640 & 16.000 \\
\hline Ramais analógicos & 640 & 50.000 \\
\hline Ramais digitais & 640 & 50.000 \\
\hline Extensões sem fio/DECT & 640 & 50.000 \\
\hline Extensões CAS/WLAN & 640 & 26.000 \\
\hline $\begin{array}{l}\text { Número de canais de tronco/de junção } \\
\text { (analógicos/T1/E1/H.323) }\end{array}$ & $99 / 230 / 240 / 250$ & 10.000 \\
\hline
\end{tabular}

\subsubsection{A SOLUÇÃO SUGERIDA}

A solução em hardware sugerida baseia-se no esquema apresentado na Figura 4.1. Ela consiste na interligação entre a central PABX MD-110 existente na Câmara e um componente MX-ONE através de uma ligação por placas Q-SIG. O MD-110 e o MX-ONE, utilizando os componentes apresentados anteriormente, possibilitam uma operação conjunta de modo que os ramais pertencentes ao MX-ONE poderão se comunicar, mantendo todas as funcionalidades e facilidades, com os ramais pertencentes ao MD-110. A idéia é utilizar o MX-ONE para possibilitar a conexão de ramais IP utilizando o protocolo SIP (o MD-110 só dá suporte ao protocolo H.323). Esses ramais IP, que poderiam estar localizados na própria Casa ou mesmo conectados a ela pela Internet, poderão estar nos gabinetes de cada deputado nos seus respectivos estados se conectarão com o MX-ONE através da rede WAN representada na Figura 4.1. Como a Internet não é uma rede segura e que não garante uma QoS mínimo requerido, a utilização de uma VPN seria de fundamental importância. 


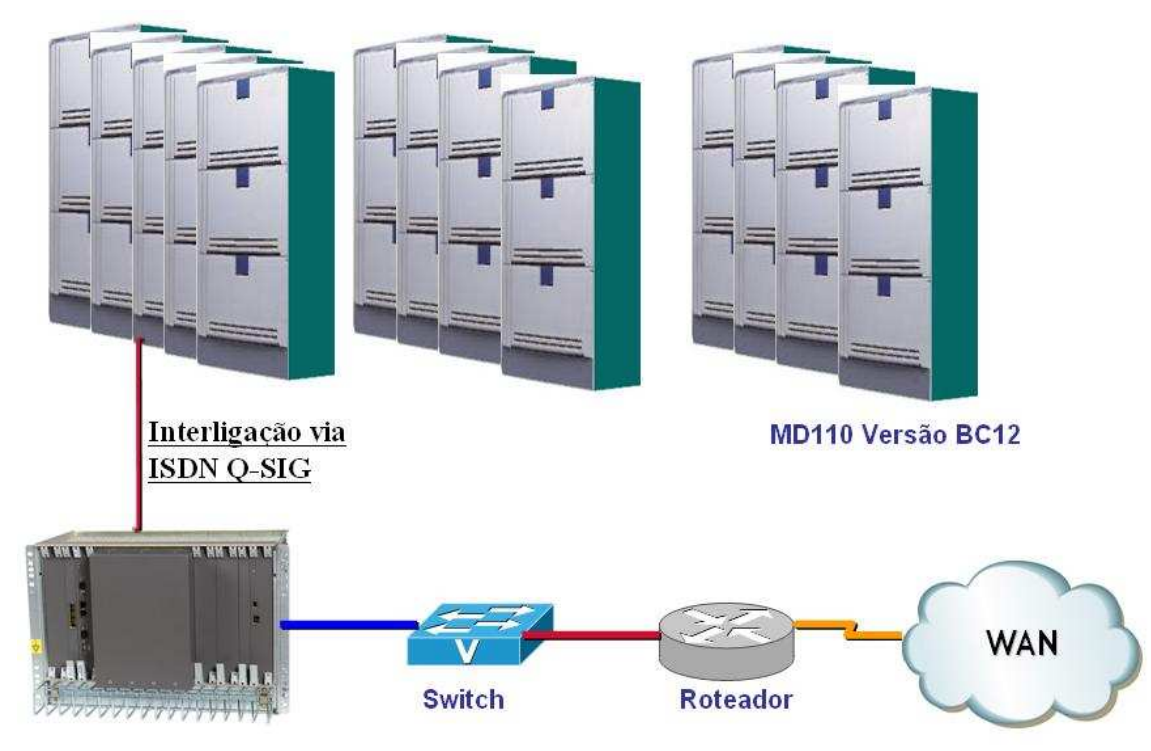

Figura 4.1- Ligação entre o PABX MD-110 e o MX-ONE

Essa ligação VoIP seria feita sempre que algum usuário no gabinete do deputado no estado tirasse o seu telefone IP do gancho para fazer uma ligação. Utilizando um provedor VPN, o telefone IP no gabinete se comunicaria diretamente com a central ampliada MX-ONE na Câmara dos Deputados em Brasília antes de fazer qualquer ligação. A chamada oficialmente partiria da central em Brasília e não do gabinete do Deputado, de forma que isso centralizaria toda a parte tarifária além de zerar os custos de ligações entre esses ramais nos estados e qualquer outro ramal pertencente ao PABX da Câmara. Além dessa possibilidade de ligação com os gabinetes nos respectivos estados dos deputados, ainda seria possível que um ramal se autenticasse de qualquer parte do mundo através de uma chamada SIP com a central telefônica da Câmara.

Outra vantagem do uso do MX-ONE para essa solução é a possibilidade de ampliação futura da central utilizando o LIM ampliado apenas inserindo placas para novos ramais (analógicos ou digitais, por exemplo). Por se tratar de um equipamento do mesmo fabricante, as placas já adquiridas pela Casa poderiam ser usadas nesse equipamento MX-ONE de modo que não seria necessário fazer qualquer adaptação futura. Mais uma vantagem desse equipamento é a operabilidade com os ramais digitais já existentes na Câmara. Os ramais digitais adquiridos pela Câmara são todos da do mesmo fabricante e só operam se conectados diretamente a centrais proprietárias. Caso fossem utilizados equipamentos de outra marca para 
essa ampliação, novos ramais digitais não poderiam ser instalados nesse equipamento. Deve ser levado em conta também que o custo de operação e manutenção de equipamentos de fabricantes diferentes seria bem maior.

Porém, se pensarmos em ampliação da central, a atual central MD-110 possibilita ainda o acoplamento de novas placas (digitais ou analógicas). Para tal ampliação, seria necessário apenas comprar mais placas e uma licença junto ao fornecedor para instalação de novos ramais. Ou seja, a central instalada atualmente na Casa possui certa capacidade de crescimento do número de ramais digitais - já licenciados. Para ampliação de ramais analógicos, seria necessário adquirir nova licença. O que é importante nisso tudo é a irrelevância se o equipamento utilizado na ampliação não possibilita ampliação utilizando aparelhos de outro fornecedor, uma vez que essa ampliação pode ser feita diretamente no MD-110 já instalado ou na parte MX-ONE.

Desde que o protocolo Q-SIG consiga manter todas as funcionalidades e facilidades entre os ramais do MD-110 e os ramais inseridos no equipamento de ampliação, não importa o fabricante do equipamento de ampliação. Porém, experiências realizadas anteriormente em outras empresas, mostraram que o uso do Q-SIG não consegue manter todas as facilidades entre a central já existente e uma nova central de outra marca. Experiências realizadas em FURNAS, por exemplo, revelaram que uma facilidade como o CallBack nunca é mantida quando PABX's de marcas diferentes são conectados através do protocolo Q-SIG.

A conexão entre o MX-ONE e o MD-110 seria feita através de placas Q-SIG. Como são do mesmo fabricante, essa interligação garantiria a permanência de todas as facilidades. As ligações com a central MD-110 seriam feitas conectando-se os troncos da placa Q-SIG com vários LIMs diferentes da parte legada. Um módulo MX-ONE se conectaria com vários LIMs de modo que fosse evitado o congestionamento dentro de um só LIM, o que ocorreria caso todas as conexões fossem feitas diretamente a apenas um LIM MD-110. Estudos de engenharia de tráfego, descrito na introdução da seção 4 foram feitos e foi, então, possível verificar que a interconexão através de 4 troncos E1 seria suficiente para dar suporte a uma ampliação de mais de 900 ramais. Como uma placa Q-SIG possui 4 portas E1, apenas uma placa já é suficiente para interconectar centrais

A arquitetura da solução em hardware está apresentada na Figura 4.2. 


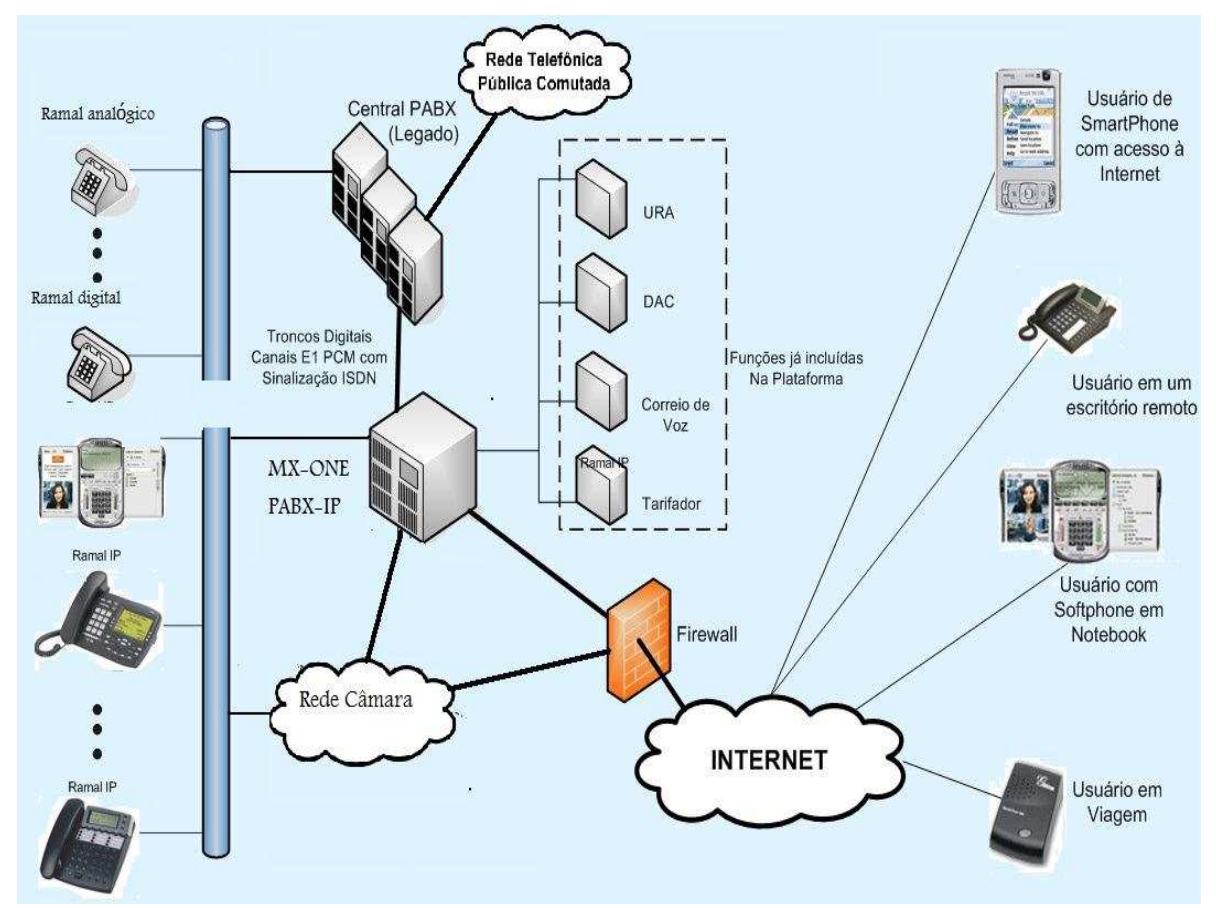

Figura 4.2 - Arquitetura da Solução em Hardware. Fonte: [Modificado de NetScience 2008]

Então, de acordo com as informações citadas acima, podemos concluir que caso seja usada a solução apresentada no esquema acima, realmente seria necessária a utilização do hardware proprietário.

Um problema dessa solução é o alto custo de implantação do sistema. Além disso, restringir o serviço a apenas um fabricante pode ser problemático em alguns casos, como, por exemplo, caso a empresa resolvesse abandonar o a tecnologia. Teria ainda o problema de que ramais digitais e ramais IP teriam sempre que ser da mesma marca. Não se poderia pensar em outro tipo de aparelho digital ou IP, visto que estes não seriam completamente transparentes para a central. 


\subsection{SOLUÇÃO EM SOFTWARE LIVRE}

Uma segunda solução que foi estudada para o cenário da Câmara dos Deputados é a solução em software livre: Asterisk. Existe um grande interesse nessa solução por se tratar de uma ferramenta em ampla expansão no mercado de telefonia IP. A escolha do PABX como a solução em software sugerida foi feita por ser ele o PABX IP em software com mais aceitação no mercado [Campos 2008].

\subsubsection{O Asterisk}

O Asterisk, como já descrito na seção 2.5, é um PABX IP em software, criado pela empresa Digium, que além de incorporar praticamente todas as funcionalidades de um PABX convencional, possui licença do tipo GPL - General Public License, isto é, é um software que para ser implementado não apresenta custos em relação a licenciamento [Gonçalves 2006].

A solução em software possibilita a implementação de serviços completos de uma operadora VoIP. A interface de operação do sistema esta dividida em três áreas distintas: URA, que faz a interação com o usuário no momento das ligações; a interface de Administração WEB que seria usada pela Câmara para gerenciamento de sistema (por exemplo: gerenciamento de faturas, tarifação, relatórios,...); e a interface com o usuário que permite ao próprio usuário acessar e verificar a situação de sua conta no sistema.

A plataforma possui interface com diversos protocolos e padrões de porta TDM, o que permite a inserção do Asterisk em ambientes legados sem dificuldade [Gonçalves 2006].

O Asterisk é uma solução que possui milhares de recursos disponíveis, como os apresentados na Figura 4.3, que torna possível o uso dos mais diversos tipos de serviços para diferentes empresas [Gonçalves 2006]. 


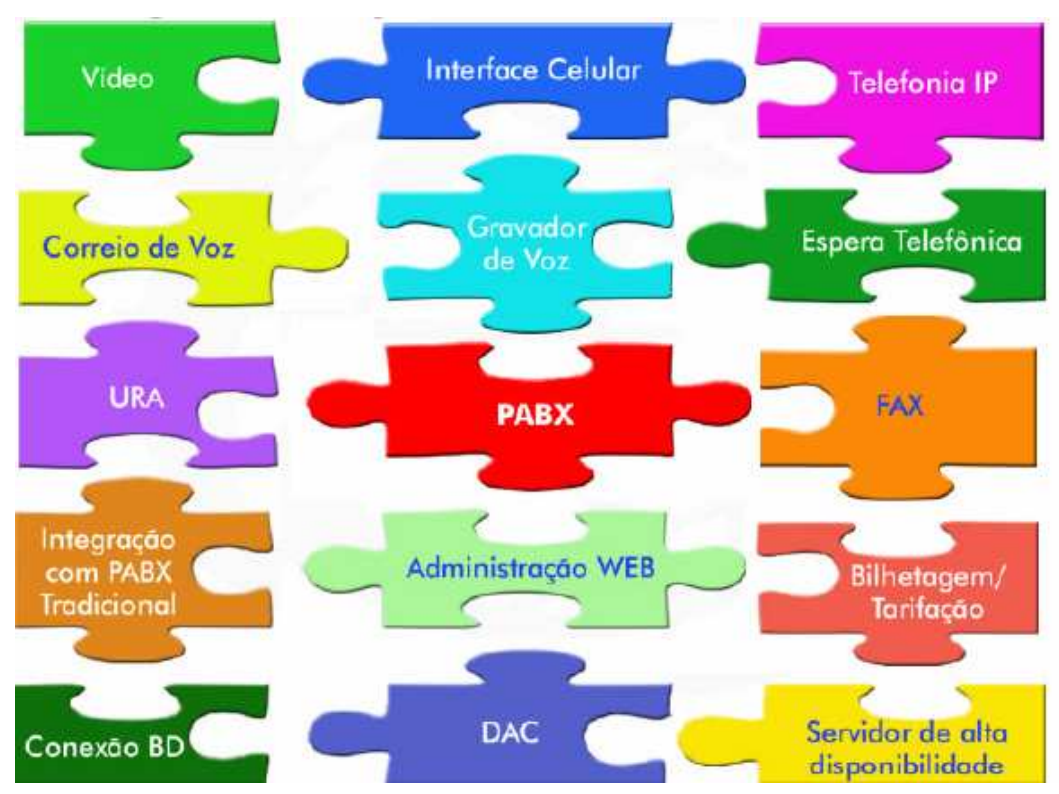

Figura 4.3 - Recursos disponíveis em um PABX IP [Lage 2006]

A grande questão que existe quanto à escolha de um PABX IP é a de qual seria a grande vantagem do Asterisk em relação a outros PABXs, como, por exemplo, o PABX em hardware apresentado na seção 4.1.1, visto que também eles podem possuir esses recursos. A resposta para essa questão é a de que o Asterisk não só dispõem desses recursos, mas faz isso de forma integrada e em software (como simbolizado na Figura 4.4), e não com diferentes equipamentos conectados a plataforma principal [Gonçalves 2006].

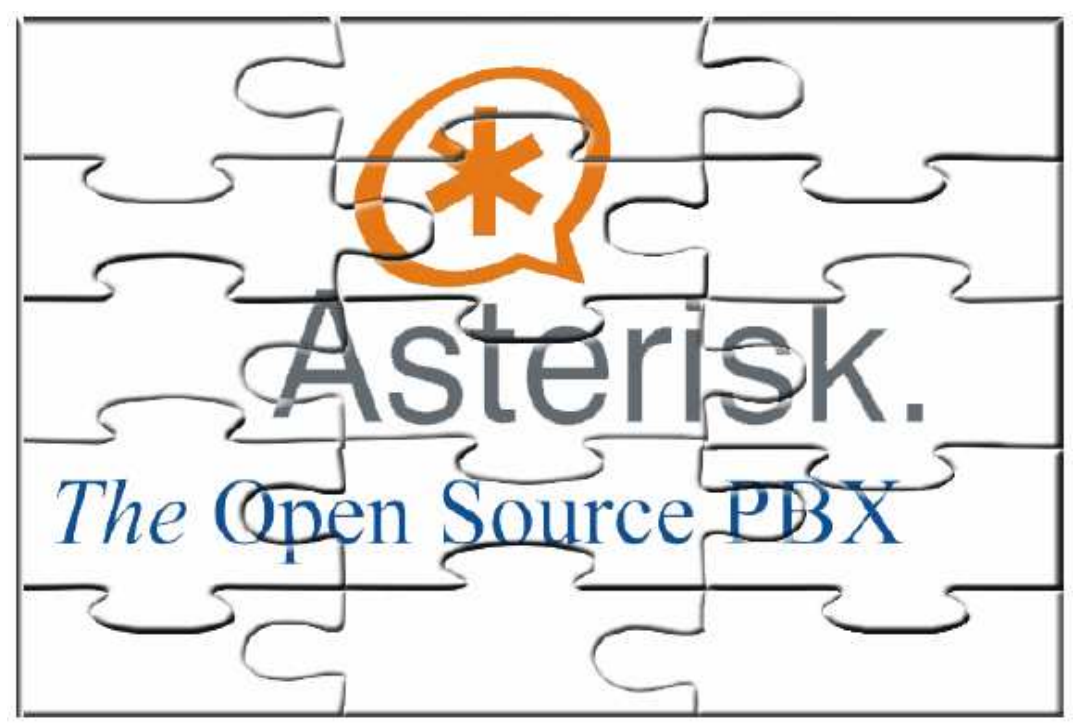

Figura 4.4 - Representação da Integração dos Recursos do PABX Asterisk [Lage 2006]h 


\subsubsection{A SOLUÇÃO ESCOLHIDA}

O Asterisk pode vir a substituir todo o sistema PABX já existente na Câmara, ou apenas se interligar a ele de forma a expandi-lo. O órgão tem o interesse de preservar os investimentos já feitos, visando a priori uma expansão que adicione ao que já existe, uma tecnologia provedora de recursos de telefonia IP.

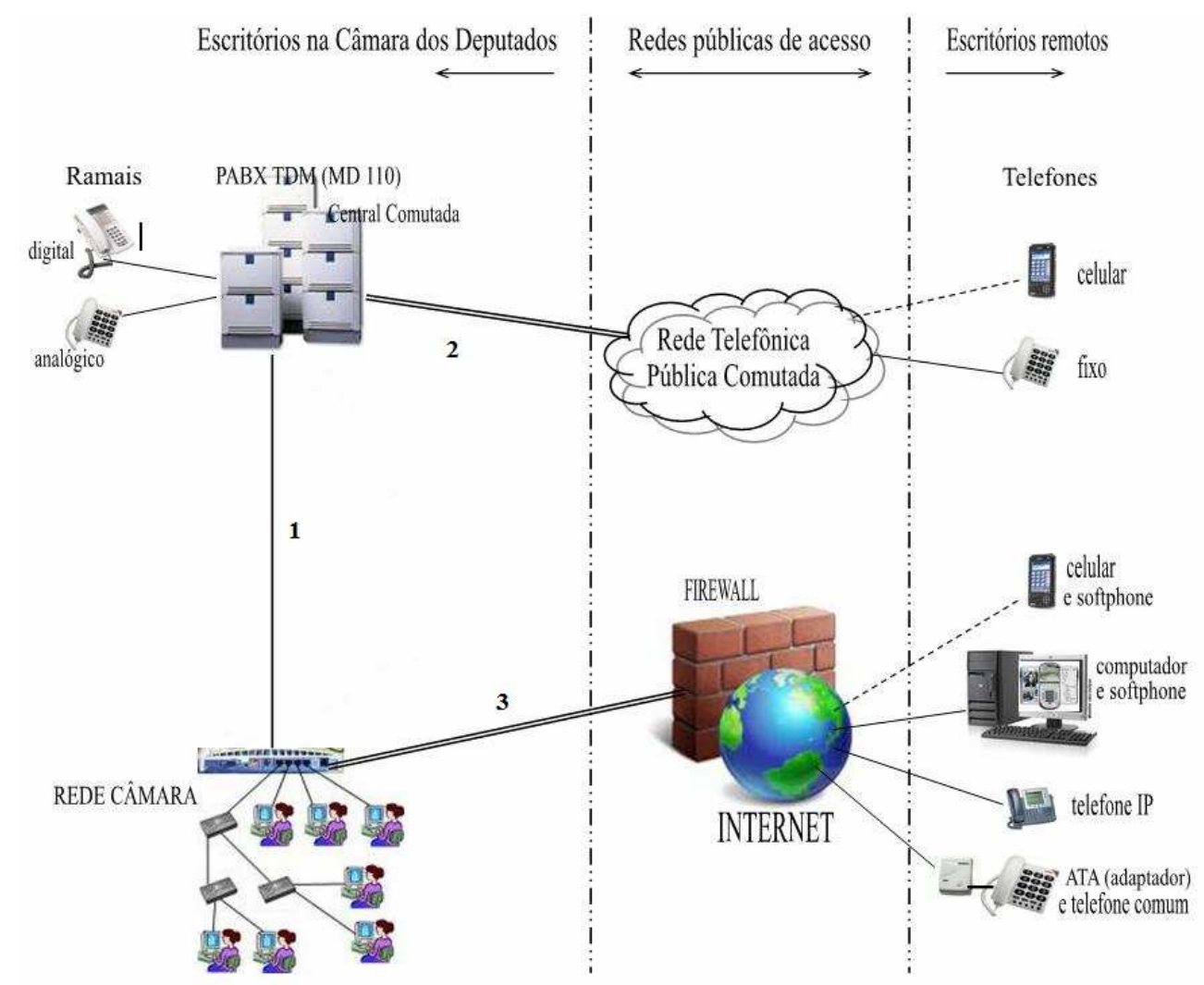

Figura 4.5 - Representação da Central Telefônica e Rede IP atual da Câmara dos Deputados

O sistema existente na Câmara está representado, de maneira simplificada, na Figura 4.5. As conexões do sistema apresentado funcionam da seguinte forma: a conexão de número 1 da Figura, existente entre a rede Câmara e a Central PABX, representa uma ligação com a rede interna de dados para o funcionamento de uma tecnologia proprietária chamada Solidus eCare [Mancini 2006]. As empresas aderem a esse tipo solução porque, como apresentado na seção 2.5.1.4, o DAC (Distribuidor Automático de Chamadas), de maneira geral, possui funcionalidades que atendem aos requisitos básicos de um Call Center. O hardware 
proprietário, MD110, entretanto, para realizar essas funções do DAC, possui um sistema de roteamento básico que é insuficiente para atender às necessidades dos clientes.

Com base nesse problema, foi, então, implementado o Solidus eCare que é uma evolução do DAC por possuir um tipo de roteamento chamado de roteamento por habilidades, conhecido no mercado pelo nome em inglês - Skill Based Routing.

A ligação de número 2 da Figura, representa as ligações do PABX interno com a RTPC. Esses enlaces representam contratos de troncos entre a Câmara e diversas empresas de telecomunicações. Atualmente a Embratel e a Brasil Telecom possuem contratos de ligação de saída para a rede de telefonia fixa. Além disso, a VIVO possui um contrato também de um tronco E1 de saída quando as ligações forem destinadas a celulares da empresa com o código de área 61. Todas as chamadas de dentro da Câmara destinadas a qualquer outro telefone (fixo ou móvel) não pertencentes a ela deverão, obrigatoriamente, passar por um desses troncos, escolhendo sempre a rota de menor custo.

Já a ligação representada pelo número 3 da Figura, trata-se de um link de 52Mbps entre a Câmara e o provedor de Internet, com as devidas configurações de segurança da informação necessárias para uma comunicação segura dentro do ambiente corporativo.

Com base na tecnologia que já existe na Casa, a solução Asterisk pode ser inserida ao sistema de acordo com uma configuração como a da Figura 4.6.

Como descrito na seção 2.5.1.5 o hardware necessário para rodar o Asterisk pode ser simplesmente um Computador Pessoal [Gonçalves 2006]. No caso, por se tratar de um ambiente com Central Telefônica de grandes proporções, foi sugerido o uso de mais de um Computador (dedicados), principalmente, por uma questão de eficiência e de geração de redundância, pois caso haja uma falha em um deles, os outros podem operar o sistema até que os devidos consertos sejam executados. 


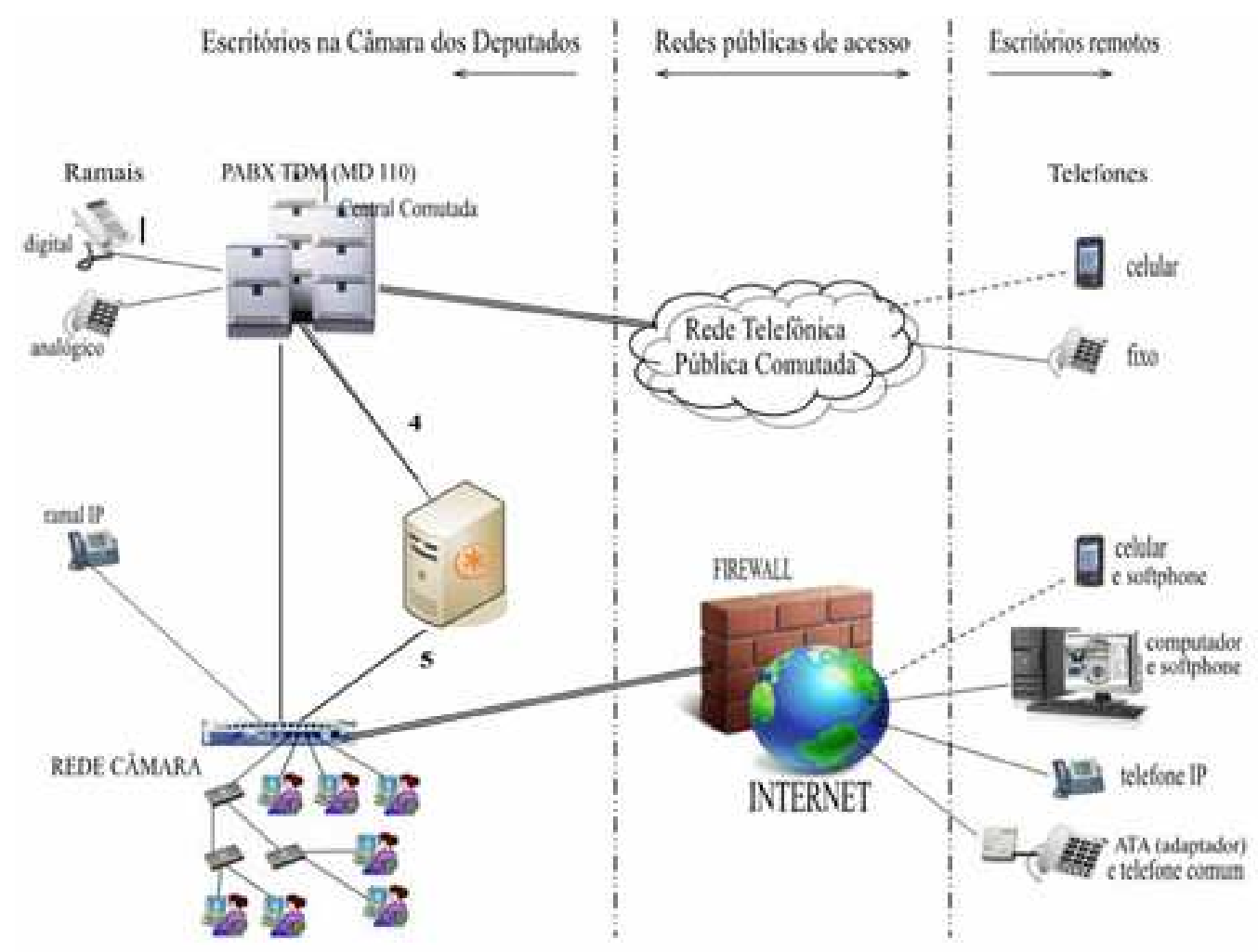

Figura 4.6 - Convergência entre Redes usando o Asterisk

Em relação à conexão entre o Asterisk e a Central PABX atual da Câmara, representada pelo número 4 na Figura 4.6, foi feito o estudo de engenharia de tráfego descrito na seção 4, e, além disso, foram estudadas algumas placas apresentadas na seção 2.5.1.5. Foi possível perceber através desse estudo que o Asterisk já possui algumas placas, homologadas pela ANATEL [Sato 2008], com 4 portas E1, que podem ser conectadas a interfaces de ramais no PABX legado, como exigido pelo sistema proposto para Câmara. Esses 4 troncos E1 deveriam ser interligados com LIMs diferentes, pois caso se interligasse todos os 4 troncos em um único LIM, isso poderia ocasionar congestionamento dentro de um LIM. Esta interligação entre o MD110 e o PC-PBX novo a ser instalado seria feita através do protocolo de sinalização Q-SIG, que permite a interoperabilidade entre equipamentos heterogêneos de centrais privadas.

A interligação indicada na Figura 4.6 pelo número 5 representa efetivamente a ligação do novo PABX-IP com a Rede Câmara para prover o serviço de telefonia sobre uma rede IP. Utilizando a rede câmara, um usuário poderia conectar um telefone IP, previamente configurado, diretamente em um cabo Ethernet conectado à rede. Este aparelho IP passaria a ser mais um ramal da Câmara, conectado ao PABX-IP através da rede câmara. Além disso, 
um usuário externo poderia utilizar o protocolo SIP para se conectar ao PABX-IP da Câmara, passando a ser um ramal virtual de onde quer que ele esteja, desde que previamente autenticado e autorizado pelos sistemas de proteção da rede câmara.

Essa última vantagem apresentada de possibilitar ramais virtuais em qualquer parte do mundo com acesso a Internet também está presente na solução MX-ONE. Porém, a solução utilizando o software livre Asterisk ainda possui maior flexibilidade e pode ser mais facilmente trabalhada nas questões relacionadas à segurança das chamadas. Uma desvantagem da solução usando Asterisk é que a documentação formal existente sobre o software é ainda um tanto deficiente [Gonçalves 2006]. Isso acaba dificultando as pesquisas devido a problemas de confiabilidades em soluções apresentadas em sites de usuários. Porém, já existem sítios na Internet feitos por grupos de usuários e desenvolvedores com ótima reputação e que permitem uma pesquisa com grande confiabilidade. A solução Asterisk representa, ainda, um avanço no rumo da adoção de softwares livres nas instituições públicas do Brasil. Atitude esta que vem se tornando cada dia mais freqüente no serviço público. 


\section{CONCLUSÃO}

Após os estudos realizados, foi possível verificar a importância desse tipo de trabalho para áreas de atuação da telefonia. A tendência na sociedade de hoje é uma convergência rápida e contínua das redes de telefonia com as redes de dados em todos os tipos de ambientes. As grandes instituições públicas, assim como as grandes empresas, precisam investir cada vez mais em tecnologias para manter operante o seu sistema telefônico legado e, não obstante, convergir sua rede para uma rede rápida, inteligente e integrada.

A partir da análise dos estudos realizados para as possíveis soluções propostas, foi possível estabelecer o melhor caminho a se seguir rumo à convergência da rede no cenário em questão. A solução em hardware que é uma solução proprietária, utilizando o MX-ONE foi apresentada como uma solução eficiente para o cenário desejado, no entanto, não é a que possibilita o melhor custo-benefício. A adoção dessa solução exigiria um alto investimento inicial para a compra do equipamento MX-ONE e ainda implicaria na continuidade de um sistema atrelado a apenas um fornecedor.

Então, a solução usando software livre se apresentou como a melhor sugestão para o problema apresentado, visto que o Asterisk possibilita a ampliação da central com um baixo investimento inicial, graças ao pequeno gasto com hardware e ao fato de ser gratuito em relação a licenciamento. O uso do software livre traz, ainda, uma série de vantagens adicionais para quem o adota como central principal ou mesmo como uma ampliação de um sistema pré-existente. Por se tratar de um software livre, existem muitos desenvolvedores ao redor do mundo trabalhando para aperfeiçoá-lo e desenvolver novas aplicações. Além disso, o seu código aberto permite até mesmo que programadores dentro da própria instituição desenvolvam códigos específicos para aplicações que se encaixem melhor nos requisitos desejados. O que demonstra a vantagem de maior flexibilidade para novas evoluções futuras.

Apesar da implantação desse novo sistema baseado em Linux acabar requerendo um novo contrato de operação e manutenção, entende-se que este é um custo adicional que compensa todas as vantagens oferecidas pelo Asterisk. Além disso, uma solução proprietária também exigiria um novo profissional para operar o sistema.

Através deste estudo, espera-se que problemas de convergência de redes em um cenário semelhante ao estudado neste trabalho possam ser mais bem entendidos e as soluções se 
tornem mais claras. Este trabalho serve de base para o entendimento da atual e intensa migração dos sistemas telefônicos corporativos convencionais para os modernos sistemas baseados em voz sobre IP de uma maneira que isso não necessariamente implique necessariamente um alto investimento. 


\section{REFERÊNCIAS BIBLIOGRÁFICAS}

ANATEL. Anexo à Resolução no 89: Regulamento de Numeração de Serviço Telefônico

Fixo Comutado, Agência Nacional de Telecomunicações, 1998.

CAMPOS, Augusto. Asterisk é o PBX mais usado do mundo. Disponível em:

http://www.linux-magazine.com.br/noticia/asterisk_e_o_pbx_mais_usado_no_mundo.

Acesso em: 15 Agosto 2009.

CISCO Systens, Understanding Codecs: Complexity, Hardware Support, MOS, and

Negotiation, Julho de 2005 URL: http://www.cisco.com.

COBB, Chey. Cryptography for Dummies. New York: For Dummies, 2004.

COLCHER, Sérgio et al. VoIP: Voz sobre IP, Rio de Janeiro: Editora Campus, 2005.

COMER, Douglas E.. Interligação em Rede com TCP/IP: Princípios, Protocolos e

Arquitetura. 2. ed. Rio de Janeiro: Editora Campus, 1998.DAVIDSON, Jonathan;

PETERS, James; BHATIA, Manoj; KALIDINDI, Satish; MUKHERJEE, Sudipto.

Voice Over IP Fundamentals. USA: Cisco Press, 2000.

ERICSSON, MX-ONE Commercial Product Description, Ericsson, 2006.

ERICSSON, MX-ONE Telephony System - Telephony Switch, Ericsson, 2006.

GARG, Vijay. Wlkireless Communications and Networking. 1 ed. Morgan Kaufmann publishers. 2006.

GREENE, Tim. Grandes empresas lideram o uso de VoIP. IDG Now!. Disponível em: <http://idgnow.uol.com.br/telecom/2006/05/18/idgnoticia > Acesso em: 20 Setembro 2008.

GONÇALVES, Flávio E. Asterisk PBX Configuration Guide. 2 ed. V.Office Networks Ltda, 2006.

HANDLEY, M. El Al. SIP - Session Initiation Protocol. Internet Engineering Task Force (IETF), Março 1999. (Request for Comments: 2543). URL: http://www.ietf.org/.

HAZARI, Sunil. Firewalls for Beginners. Disponível em: <http://www.securityfocus.com/infocus/1182>. Acesso em: 11 Maio 2009.

JESZENSKY, Paul Jean Etiennne. Sistemas Telefônicos, Barueri: Manole, 2004. 


\section{KAMIENSKI, C. A.; SADOK, J. Engenharia de Tráfego em uma Rede de Serviços}

Integrados. In: $18^{\circ}$ Simpósio Brasileiro de Redes de Computadores, Anais: SBRC 2000, Belo Horizonte, MG, 23 a 26 de maio de 2000.

LAGE, Epaminondas. Como Explorar os Recursos do Asterisk, 2006. Disponível em: http://dicasasterisk.asteriskonline.com.br/?p=108. Acesso em: 4 Julho 2009.

LEMOS, Guido; SOARES, Luiz Fernando Gomes; COLCHER, Sérgio. Redes de Computadores: Das LANs, MANs e WANs às Redes ATM. 2. Ed. Rio de Janeiro: Campus, 1995.

MANCINI, Lucas. Call Center: Estratégia para Vencer. 1. Ed. Summus Editorial, 2006.

MEGGELEN, Jim Van; MADSEN, Leif; SMITH, Jared. Asterisk: The Future of Telephony. 2. Ed. O’Reilly Media, 2007.

NETSCIENCE, Proposta de Plataforma de Serviços NetScience, NetScience, 2008.

OLIVERIA, Flávio de Souza. Asterisk: o nome da revolução no Mercado de telefonia. PC \& CIA 81: 53-59, 2008.

PRADO, Eduardo e Lima, Fabio. Dimensionamento de Redes WiMAX, Disponível em : $\langle$ http://www.teleco.com.br/tutoriais/tutorialredeswimax/pagina_3.asp $>$. Acesso em 28 Abril 2009.

RAPPAPORT, Theodore S.. Wireless communications: principles and practice. 2 nd ed. Upper Saddle River, NJ: Prentice Hall, 2002.

R. NETO, Almerindo; D. JÚNIOR, Israel. VoIP e Linux: Montando um PBX Gratuito. Aracajú, 2006.

SATO, Alberto Mitsuo. PABX IP. Disponível em: <http://www.teleco.com.br/tutoriais/tutorialpabx/default.asp>. Acesso em: 1 Abril 2009. SATO, Alberto Mitsuo. Placas DigiVoice: Homologação Anatel, 2008. Disponível em: <http://www.albertosato.voipcenter.com.br/?p=530>. Acesso em: 2 Junho 2009. 
ANEXO A - Tabela Erlang B

\begin{tabular}{|c|c|c|c|c|c|c|c|c|c|}
\hline $\mathrm{P}(\mathrm{B})=$ Trunks & 0.01 & 0.015 & 0.02 & 0.03 & 0.05 & 0.07 & 0.1 & 0.2 & 0.5 \\
\hline 1 & 0.010 & 0.015 & 0.020 & 0.031 & 0.053 & 0.075 & 0.111 & 0.250 & 1.000 \\
\hline 2 & 0.153 & 0.190 & 0.223 & 0.282 & 0.381 & 0.471 & 0.595 & 1.000 & 2.732 \\
\hline 3 & 0.455 & 0.536 & 0.603 & 0.715 & 0.899 & 1.057 & 1.271 & 1.930 & 4.591 \\
\hline 4 & 0.870 & 0.992 & 1.092 & 1.259 & 1.526 & 1.748 & 2.045 & 2.944 & 6.501 \\
\hline 5 & 1.361 & 1.524 & 1.657 & 1.877 & 2.219 & 2.504 & 2.881 & 4.010 & 8.437 \\
\hline 6 & 1.913 & 2.114 & 2.277 & 2.544 & 2.961 & 3.305 & 3.758 & 5.108 & 10.389 \\
\hline 7 & 2.503 & 2.743 & 2.936 & 3.250 & 3.738 & 4.139 & 4.666 & 6.229 & 12.351 \\
\hline 8 & 3.129 & 3.405 & 3.627 & 3.987 & 4.543 & 4.999 & 5.597 & 7.369 & 14.318 \\
\hline 9 & 3.783 & 4.095 & 4.345 & 4.748 & 5.370 & 5.879 & 6.546 & 8.521 & 16.293 \\
\hline 10 & 4.462 & 4.808 & 5.084 & 5.529 & 6.216 & 6.776 & 7.511 & 9.684 & 18.271 \\
\hline 11 & 5.160 & 5.539 & 5.842 & 6.328 & 7.076 & 7.687 & 8.487 & 10.857 & 20.253 \\
\hline 12 & 5.876 & 6.287 & 6.615 & 7.141 & 7.950 & 8.610 & 9.477 & 12.036 & 22.237 \\
\hline 13 & 6.607 & 7.049 & 7.402 & 7.967 & 8.835 & 9.543 & 10.472 & 13.222 & 24.223 \\
\hline 14 & 7.352 & 7.824 & 8.200 & 8.803 & 9.730 & 10.485 & 11.475 & 14.412 & 26.211 \\
\hline 15 & 8.108 & 8.610 & 9.010 & 9.650 & 10.633 & 11.437 & 12.485 & 15.608 & 28.200 \\
\hline 16 & 8.875 & 9.406 & 9.828 & 10.505 & 11.544 & 12.363 & 13.501 & 16.807 & 30.190 \\
\hline 17 & 9.652 & 10.211 & 10.656 & 11.368 & 12.465 & 13.355 & 14.523 & 18.010 & 32.181 \\
\hline 18 & 10.450 & 11.024 & 11.491 & 12.245 & 13.389 & 14.323 & 15.549 & 19.215 & 34.173 \\
\hline 19 & 11.241 & 11.854 & 12.341 & 13.120 & 14.318 & 15.296 & 16.580 & 20.424 & 36.166 \\
\hline 20 & 12.041 & 12.680 & 13.188 & 14.002 & 15.252 & 16.273 & 17.614 & 21.635 & 38.159 \\
\hline
\end{tabular}




\begin{tabular}{|c|c|c|c|c|c|c|c|c|}
\hline $\mathrm{P}(\mathrm{B})=$ Trunks & 0.005 & 0.01 & 0.015 & 0.02 & 0.03 & 0.05 & 0.07 & 0.1 \\
\hline 21 & 11.860 & 12.848 & 13.514 & 14.042 & 14.890 & 16.191 & 17.255 & 18.652 \\
\hline 22 & 12.635 & 13.660 & 14.352 & 14.902 & 15.782 & 17.134 & 18.240 & 19.693 \\
\hline 23 & 13.429 & 14.479 & 15.196 & 15.766 & 16.679 & 18.082 & 19.229 & 20.737 \\
\hline 24 & 14.214 & 15.303 & 16.046 & 16.636 & 17.581 & 19.033 & 20.221 & 21.784 \\
\hline 25 & 15.007 & 16.132 & 16.900 & 17.509 & 18.486 & 19.987 & 21.216 & 22.834 \\
\hline 26 & 15.804 & 16.966 & 17.758 & 18.387 & 19.395 & 20.945 & 22.214 & 23.885 \\
\hline 27 & 16.607 & 17.804 & 18.621 & 19.269 & 20.308 & 21.905 & 23.214 & 24.939 \\
\hline 28 & 17.414 & 18.646 & 19.487 & 20.154 & 21.224 & 22.869 & 24.217 & 25.995 \\
\hline 29 & 18.226 & 19.493 & 20.357 & 21.043 & 22.143 & 23.835 & 25.222 & 27.053 \\
\hline 30 & 19.041 & 20.343 & 21.230 & 21.935 & 23.065 & 24.835 & 26.229 & 28.113 \\
\hline 31 & 19.861 & 21.196 & 22.107 & 22.830 & 23.989 & 25.774 & 27.239 & 29.174 \\
\hline 32 & 20.685 & 22.053 & 22.987 & 23.728 & 24.917 & 26.747 & 28.250 & 30.237 \\
\hline 33 & 21.512 & 22.913 & 23.869 & 24.629 & 25.846 & 27.722 & 29.263 & 31.302 \\
\hline 34 & 22.342 & 23.776 & 24.755 & 25.532 & 26.778 & 28.699 & 30.277 & 32.367 \\
\hline 35 & 23.175 & 24.642 & 25.643 & 26.438 & 27.712 & 29.678 & 31.294 & 33.435 \\
\hline 36 & 24.012 & 25.511 & 26.534 & 27.346 & 28.649 & 30.658 & 32.312 & 34.503 \\
\hline 37 & 24.852 & 26.382 & 27.427 & 28.256 & 29.587 & 31.641 & 33.331 & 35.572 \\
\hline 38 & 25.694 & 27.256 & 28.322 & 29.168 & 30.527 & 32.624 & 34.351 & 36.643 \\
\hline 39 & 26.539 & 28.132 & 29.219 & 30.083 & 31.469 & 33.610 & 35.373 & 37.715 \\
\hline 40 & 27.387 & 29.011 & 30.119 & 30.999 & 32.413 & 34.597 & 36.397 & 38.788 \\
\hline 41 & 28.237 & 29.891 & 31.021 & 31.918 & 33.359 & 35.585 & 37.421 & 39.861 \\
\hline 42 & 29.089 & 30.774 & 31.924 & 32.838 & 34.306 & 36.575 & 38.447 & 40.936 \\
\hline 43 & 29.944 & 31.659 & 32.830 & 33.760 & 35.255 & 37.565 & 39.473 & 42.012 \\
\hline 44 & 30.801 & 32.546 & 33.737 & 34.683 & 36.205 & 38.558 & 40.501 & 43.088 \\
\hline 45 & 31.660 & 33.435 & 34.646 & 35.609 & 37.156 & 39.551 & 41.530 & 44.165 \\
\hline 46 & 32.521 & 34.325 & 35.556 & 36.535 & 38.109 & 40.545 & 42.559 & 45.243 \\
\hline 47 & 33.385 & 35.217 & 36.468 & 37.463 & 39.063 & 41.541 & 43.590 & 46.322 \\
\hline 48 & 34.250 & 36.111 & 37.382 & 38.393 & 40.019 & 42.537 & 44.621 & 47.401 \\
\hline 49 & 35.116 & 37.007 & 38.297 & 39.324 & 40.976 & 43.535 & 45.654 & 48.481 \\
\hline 50 & 35.985 & 37.904 & 39.214 & 40.257 & 41.934 & 44.534 & 46.687 & 49.562 \\
\hline 51 & 36.856 & 38.802 & 40.132 & 41.190 & 42.893 & 45.533 & 47.721 & 50.644 \\
\hline
\end{tabular}




\begin{tabular}{|c|c|c|c|c|c|c|c|c|}
\hline 52 & 37.728 & 39.702 & 41.052 & 42.125 & 43.853 & 46.533 & 48.756 & 51.726 \\
\hline 53 & 38.601 & 40.604 & 41.972 & 43.061 & 44.814 & 47.535 & 49.791 & 52.808 \\
\hline 54 & 9.477 & 41.507 & 42.894 & 43.999 & 45.777 & 48.537 & 50.827 & 53.891 \\
\hline 55 & 40.354 & 42.411 & 43.817 & 44.937 & 46.740 & 49.540 & 51.864 & 54.975 \\
\hline 56 & 41.232 & 43.317 & 44.742 & 45.877 & 47.704 & 50.544 & 52.902 & $56 .-59$ \\
\hline 57 & 42.112 & 44.224 & 45.667 & 46.817 & 48.689 & 52.548 & 53.940 & 57.144 \\
\hline 58 & 42.993 & 45.132 & 46.594 & 47.759 & 49.636 & 52.553 & 54.979 & 58.229 \\
\hline 5 & 43.875 & 46.041 & 47.522 & 48.701 & 50.603 & 53.559 & 56.018 & 59.315 \\
\hline 60 & 44.759 & 46.951 & 48.451 & 49.645 & 51.570 & 54.566 & 57.058 & 60.401 \\
\hline 6 & 45.644 & 47.863 & 49.381 & 50.590 & 52.539 & 55.573 & 58.099 & 61.488 \\
\hline 62 & 46.531 & 48.776 & 50.311 & 51.535 & 53.509 & 56.581 & 59.140 & 62.575 \\
\hline 63 & 47.418 & 49.689 & 51.243 & 52.482 & 54.479 & 57.590 & 60.181 & 63.663 \\
\hline 64 & 48.307 & 50.604 & 52.176 & 53.429 & 55.450 & 58.599 & 61.224 & 64.750 \\
\hline 65 & 49.197 & 51.520 & 53.110 & 54.377 & 56.422 & 59.609 & 62.266 & 65.839 \\
\hline 66 & 50.088 & 52.437 & 54.044 & 55.326 & 57.395 & 60.620 & 63.309 & 66.927 \\
\hline 67 & 50.980 & 53.355 & 54.980 & 56.276 & 58.368 & 61.631 & 64.353 & 68.016 \\
\hline 68 & 51.874 & 54.273 & 55.916 & 57.226 & 59.342 & 62.642 & 65.397 & 69.106 \\
\hline 69 & 52.768 & 55.193 & 56.853 & 58.178 & 60.316 & 63.654 & 66.442 & 70.196 \\
\hline 70 & 53.663 & 56.113 & 57.791 & 59.130 & 61.292 & 64.667 & 67.487 & 71.286 \\
\hline 71 & 56.560 & 57.035 & 58.730 & 60.083 & 62.268 & 65.680 & 68.532 & 72.376 \\
\hline 72 & 55.457 & 57.957 & 59.670 & 61.036 & 63.244 & 66.694 & 69.578 & 73.467 \\
\hline 73 & 56.356 & 58.880 & 60.610 & 61.991 & 64 & 67.708 & 70.624 & 74.558 \\
\hline 74 & 57.255 & 59.804 & 61.551 & 62.945 & 65.199 & 68.723 & 71.671 & 75.649 \\
\hline 75 & 58.155 & 60.729 & 62.493 & 63.901 & 66.178 & 69.738 & 72.718 & 76.741 \\
\hline 76 & 59.056 & 61.654 & 63.435 & 64.857 & 67.157 & 70.753 & 73.718 & 77.833 \\
\hline 77 & 59.958 & 62.581 & 64.379 & 65.814 & 68.136 & 71.769 & 74.813 & 78.925 \\
\hline 78 & 60.861 & 63.508 & 65.322 & 66.772 & 69.116 & 72.786 & 75.861 & 80.018 \\
\hline 7 & 61.765 & 64.435 & 66.267 & 67.730 & 70.097 & 73.803 & 76.909 & 81.110 \\
\hline 80 & 62.669 & 65.364 & 67.212 & 68.689 & 71.078 & 74.820 & 77.958 & 82.203 \\
\hline 81 & 63.574 & 66.293 & 68.158 & 69.648 & 72.059 & 75.838 & 79.007 & 83.297 \\
\hline 82 & 64.481 & 67.223 & 69.104 & 70.608 & 73.042 & 76.856 & 80.057 & 84.390 \\
\hline 83 & 65.387 & 68.153 & 70.051 & 71.568 & 74.024 & 77.874 & 81.107 & 85.484 \\
\hline 84 & 66.295 & 69.085 & 70.999 & 72.529 & 75.007 & 78.893 & 82.157 & 86.578 \\
\hline
\end{tabular}




\begin{tabular}{|c|c|c|c|c|c|c|c|c|}
\hline 85 & 67.204 & 70.016 & 71.947 & 73.491 & 75.991 & 79.912 & 83.207 & 87.672 \\
\hline 86 & 68.113 & 70.949 & 72.896 & 74.453 & 76.975 & 80.932 & 84.258 & 88.767 \\
\hline 87 & 9.023 & 71.882 & 73.846 & 75.416 & .959 & .952 & 85.309 & 89.861 \\
\hline 88 & 69.933 & 72.816 & 74.796 & 76.379 & 78.944 & 82.972 & 86.360 & 90.956 \\
\hline 89 & 70.844 & 73.750 & 75.746 & 77.342 & 79.929 & 83.993 & 87.411 & 92.051 \\
\hline 90 & 71.756 & 74.685 & 76.697 & 78.306 & 80.915 & 85.014 & 88.463 & 93.146 \\
\hline 91 & 72.669 & 75.621 & 77.649 & 79.271 & 81.901 & 86.035 & 89.515 & 94.242 \\
\hline 92 & 73.582 & 76.557 & 78.601 & 80.236 & 888 & .057 & 0.568 & 95.338 \\
\hline 9 & 74.496 & 77.493 & 79.553 & 202 & .875 & .079 & 91.620 & .434 \\
\hline 94 & 75.411 & 78.431 & 80.506 & 82.167 & 84.862 & 89.101 & 92.673 & 97.530 \\
\hline 05 & 76.326 & 79.368 & 81.460 & 83.134 & 85.850 & 90.123 & 93.726 & 98.626 \\
\hline 96 & 77.242 & 80.307 & 82.414 & 84.101 & 86.838 & 91.146 & 94.779 & 99.722 \\
\hline 97 & 78.158 & 81.245 & 83.368 & 85.068 & 87.827 & 92.169 & 95.833 & 100.819 \\
\hline 98 & 79.075 & 82.185 & 84.323 & 86.036 & 88.815 & 93.193 & 96.887 & 101.916 \\
\hline 99 & 79.993 & 83.125 & 85.279 & 87.004 & 89.805 & 94.217 & 97.941 & 103.013 \\
\hline 100 & 80.911 & 84.065 & 86.235 & 87.972 & 90.794 & 95.240 & 98.995 & 104.110 \\
\hline 105 & 85.518 & 88.822 & 91.030 & 92.823 & 95.747 & 100.371 & 104.270 & 109.598 \\
\hline 110 & 90.147 & 93.506 & 95.827 & 97.687 & 100.713 & 105.496 & 109.550 & 115.090 \\
\hline 115 & 94.768 & 98.238 & 100.631 & 102.552 & 105.680 & 110.632 & 114.833 & 120.585 \\
\hline 120 & 99.402 & 102.977 & 105.444 & 107.426 & 110.655 & 115.772 & 120.121 & 126.083 \\
\hline 125 & 104.047 & 107.725 & 110.265 & 112.307 & 115.636 & 120.918 & 125.413 & 131.583 \\
\hline 130 & 8.702 & 112.482 & 115.094 & 117.195 & 120.622 & 126.068 & 130.708 & 137.087 \\
\hline 135 & 13.366 & 117.247 & 119.930 & 122.089 & 125.615 & 131.222 & 136.007 & 142.593 \\
\hline 140 & 118.039 & 122.019 & 124.773 & 126.990 & 130.612 & 136.380 & 141.309 & 148.101 \\
\hline 145 & 122.720 & 126.798 & 129.622 & 131.896 & 135.614 & 141.542 & 146.613 & 153.611 \\
\hline 150 & 127.410 & 131.584 & 134.477 & 136.807 & 140.621 & 146.707 & 151.920 & 159.122 \\
\hline 155 & 132.106 & 136.377 & 139.337 & 141.724 & 145.632 & 151.875 & 157.230 & 164.636 \\
\hline 160 & 136.810 & 141.175 & 203 & 545 & 15 & 15 & 42 & 170. \\
\hline 165 & 141.520 & 145.979 & 149.074 & 151.571 & 155.665 & 162.221 & 167.856 & 175.668 \\
\hline 170 & 146.237 & 150.788 & 153.949 & 156.501 & 160.688 & 167.398 & 173.173 & 181.187 \\
\hline 175 & 150.959 & 155.602 & 158.829 & 161.435 & 165.713 & 172.577 & 178.491 & 186.706 \\
\hline 180 & 155.687 & 160.422 & 163.713 & 166.373 & 170.742 & 177.759 & 183.811 & 192.227 \\
\hline 185 & 160.421 & 165.246 & 168.602 & 171.315 & 175.774 & 182.943 & 189.133 & 197.75 \\
\hline
\end{tabular}


$\begin{array}{lllllllll}190 & 165.160 & 170.074 & 173.494 & 176.260 & 180.809 & 188.129 & 194.456 & 203.273\end{array}$

$\begin{array}{lllllllll}200 & 174.653 & 179.743 & 183.289 & 186.161 & 190.887 & 198.508 & 205.108 & 214.323\end{array}$ 